\title{
Water Power Calculator Temperature and Analog Input/Output Module Ambient Temperature Testing
}

\author{
Mark D. McKay
}

February 2011

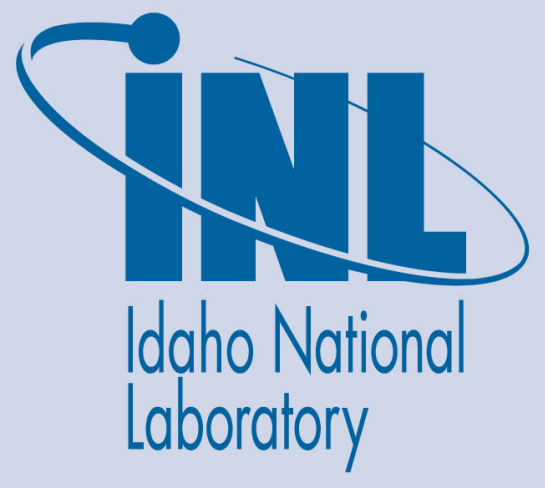

The INL is a U.S. Department of Energy National Laboratory operated by Battelle Energy Alliance 


\title{
Water Power Calculator Temperature and Analog Input/Output Module Ambient Temperature Testing
}

\author{
Mark D. McKay
}

February 2011

Idaho National Laboratory Idaho Falls, Idaho 83415

http://www.inl.gov

Prepared for the U.S. Department of Energy Office of Nuclear Energy Under DOE Idaho Operations Office Contract DE-AC07-05ID14517 


\section{DISCLAIMER}

This information was prepared as an account of work sponsored by an agency of the U.S. Government. Neither the U.S. Government nor any agency thereof, nor any of their employees, makes any warranty, expressed or implied, or assumes any legal liability or responsibility for the accuracy, completeness, or usefulness, of any information, apparatus, product, or process disclosed, or represents that its use would not infringe privately owned rights. References herein to any specific commercial product, process, or service by trade name, trade mark, manufacturer, or otherwise, does not necessarily constitute or imply its endorsement, recommendation, or favoring by the U.S. Government or any agency thereof. The views and opinions of authors expressed herein do not necessarily state or reflect those of the U.S. Government or any agency thereof. 
Robotics \& Intelligent Systems

\section{Water Power Calculator Temperature and Analog inputloutput Module Ambient Temperature Testing}

February 2011
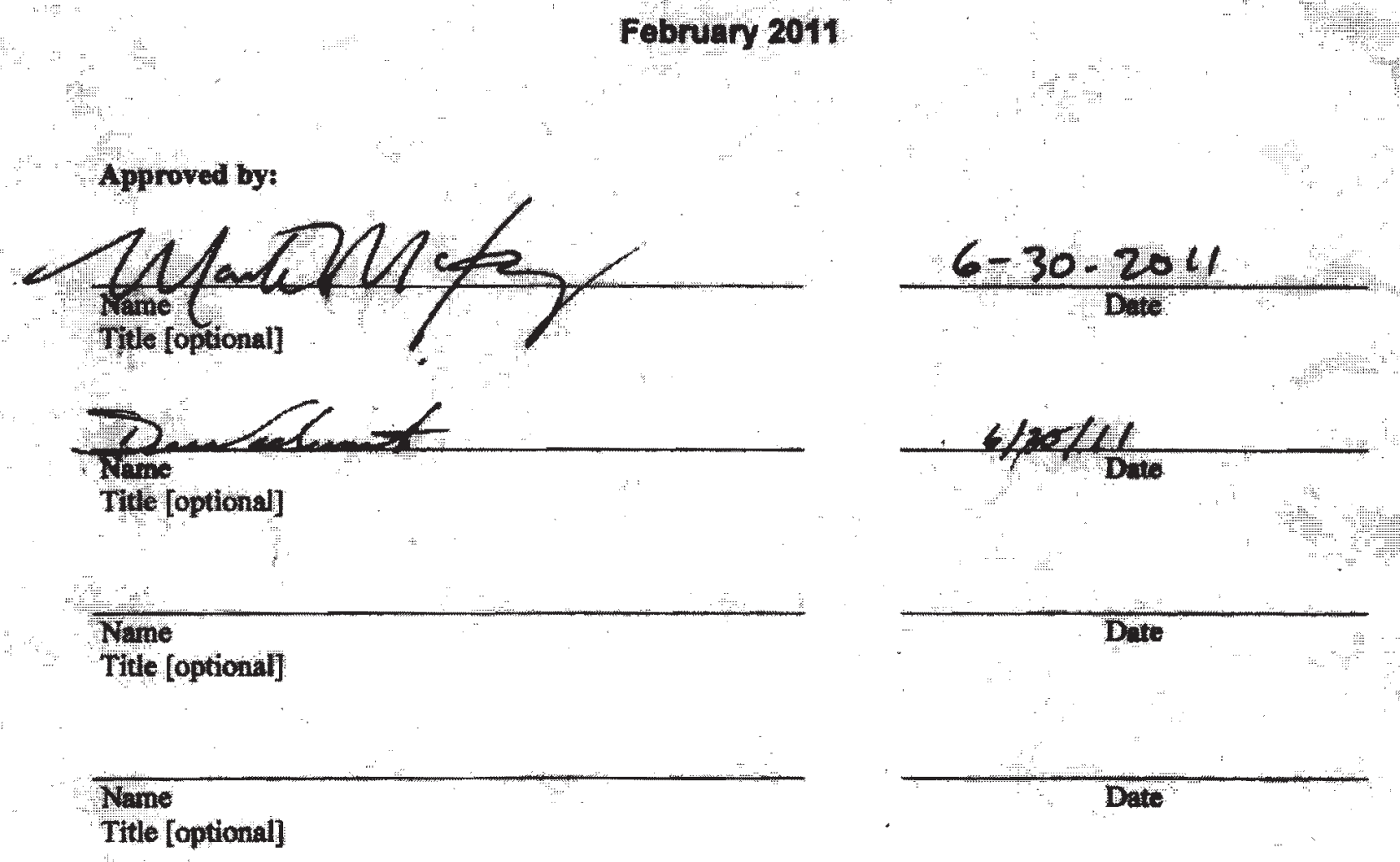

Title [optional] 


\section{CONTENTS}

ABSTRACT, SUMMARY, FOREWORD, AND ACKNOWLEDGEMENTSError! Bookmark not defined.

ACRONYMS viii

1. Scope …

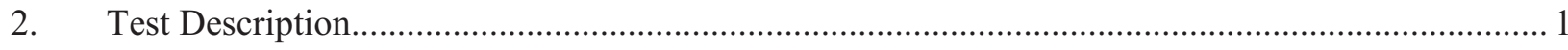

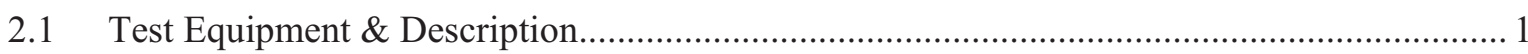

2.21

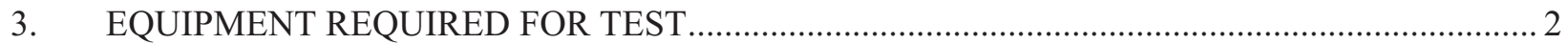

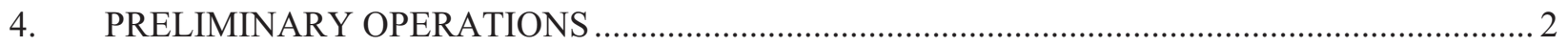

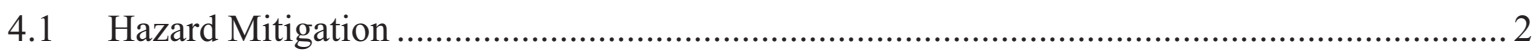

4.1.1 The operation of the Tenney Environmental Chamber and any Calibration

Laboratory Equipment is RESTRICTED to Qualified Standards and

Calibration Laboratory (S\&CL) Calibration Technicians trained to the hazards and the hazard controls identified by LI-13476, "Standards and Calibration Laboratory Hazard Identification and Mitigation."

4.1.2 Place the unit under test (UUT) and standard thermometer within close proximity of each other (3.2) inside the Temperature Chamber (3.1) ...................... 2

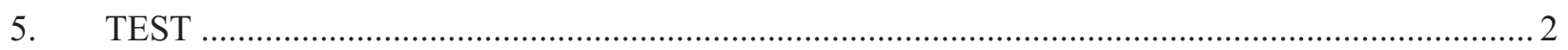

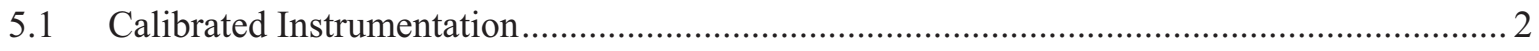

5.1.1 The following equipment was used for this test: ................................................. 2

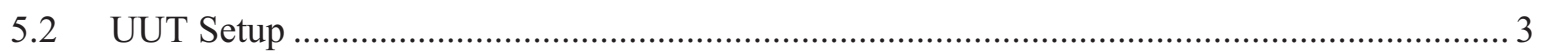

5.2.1 Setup the UUT equipment in the Chamber and make necessary connections............ 3

5.2.2 Connect UUT to the Water Power Calculator Data Recorder (Honeywell

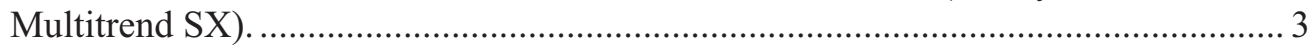

5.2.3 Program to the Water Power Calculator Data Recorder to record data once every 20 seconds for each channel (pen) for each of the AIM, AOM and TIM modules.

5.2.4 Synchronize the Honeywell SX data recorder time with the computer recording the test chamber data. This can be done by using the built in NTP server or by manually setting the Recorder clock to match the test chamber's

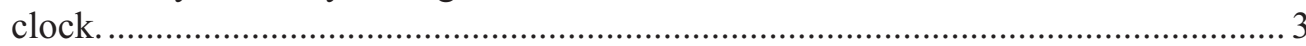

5.3 Temperature Measurement...................................................................................... 3

5.3.1 Perform a 37-point check of the applicable UUT temperature range. Set the temperature chamber to the first temperature checkpoint......................................... 3

5.3.2 Allow adequate time for chamber and instrument stabilization................................ 3

5.3.3 Using the Standard Thermometer (3.2), verify that the UUT reads within the stated accuracy given in Appendix A...................................................................... 3

5.3.4 Record the Analog input voltage levels prior to the start of each test........................ 3

5.3.5 Repeat Steps 5.1.2 and 5.1.3 for the remaining checkpoints as detailed in Table 1 below.

5.3.6 If necessary Repeat Steps 5.1.1 to 5.1.4 to achieve the three consecutive tests. 


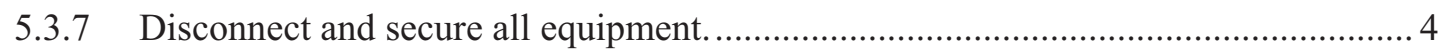

5.4 If the UUT has humidity measurement capabilities, calibrate using S\&CL CWI-

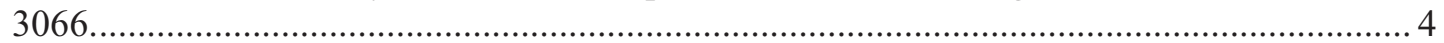

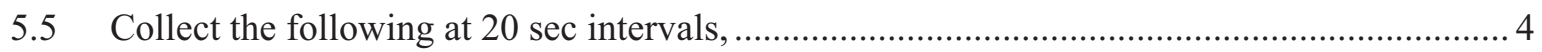

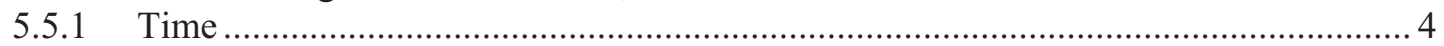

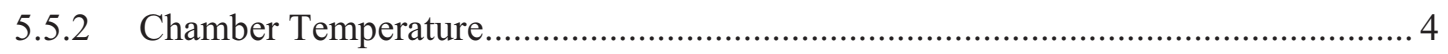

5.5.3 Laboratory Ambient Temperature, with temperature probe with in one to two inches of the test subject terminal block. ............................................................ 4

5.5.4 Chamber percent relative humidity $(\% \mathrm{RH})$.................................................... 4

5.6 Turn Temperature Chamber (3.1) off and allow the inside temperature to cool to a

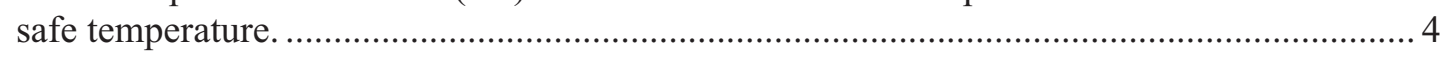

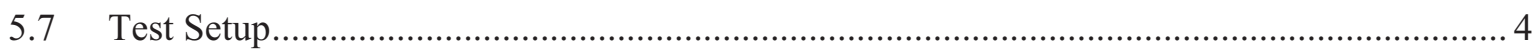

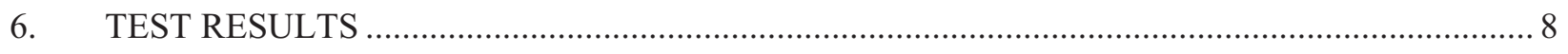

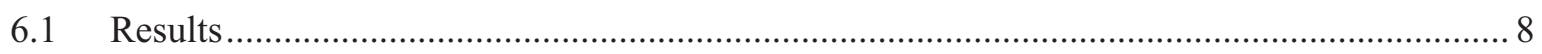

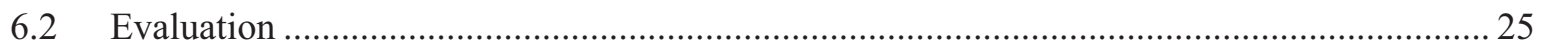

6.2.1 Variability in the data for each of the channels is shown in the following tables. The units for each channel are as follows:..................................................... 25

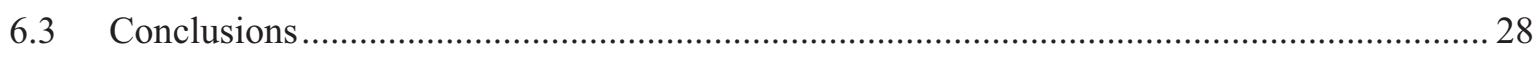

6.3.1 The ambient temperature test results demonstrate that the Moore Industries TIMs, AIM and AOM ambient temperature response meet or exceed the manufactures specifications. ........................................................................... 28

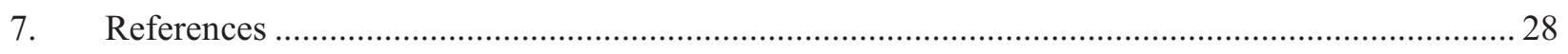

7.1 Moore Industries-International, Inc, NCS specifications................................................. 28

7.2 JCGM 200:2008 International vocabulary of metrology - Basic and general

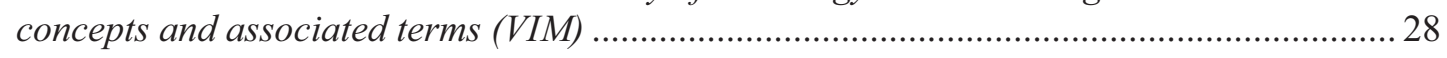

\section{FIGURES}

Figure 1 Test equipment and Tenney Chamber (from left to right, Moore modules, sensor terminal block, Honeywell recorder, Tenney Chamber) ....................................................... 5

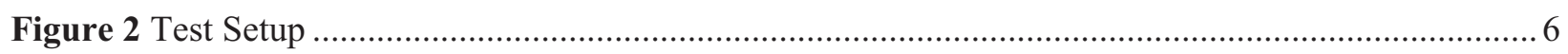

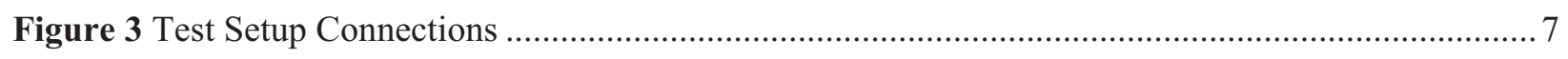

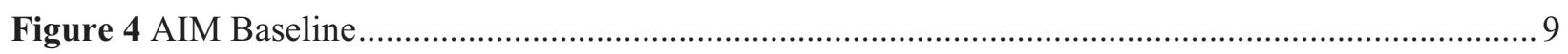

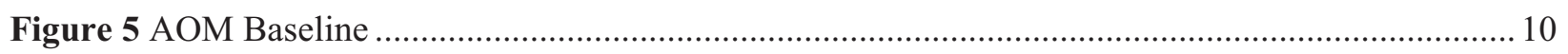

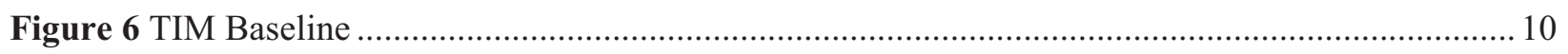

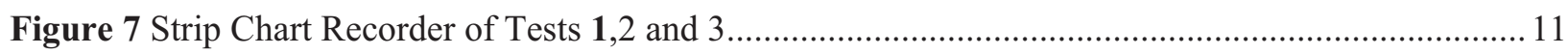

Figure 8 Ambient Laboratory Temperature (outside of chamber) ........................................................ 12

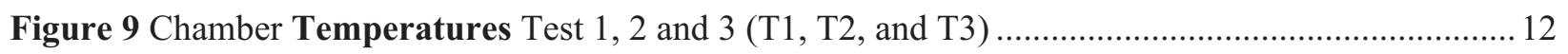

Figure $10 \%$ Relative Humidity vs. Time inside of the Chamber....................................................... 13

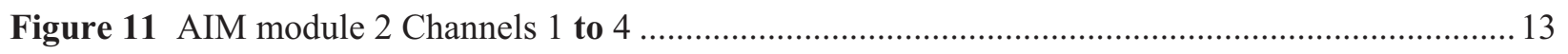

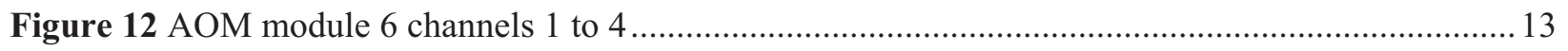




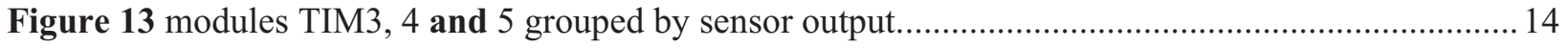

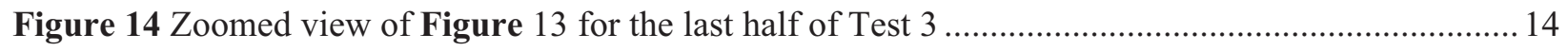

Figure 15 AIM Module 2 Channels 1 to 4 Temperature vs. Time........................................................ 15

Figure 16 AOM Module 6 Channels 1 to 4 Temperature vs. Time .................................................... 15

Figure 17 TIM Modules 3,4, and 5 Channels 1 to 4 Temperature vs. Time........................................... 16

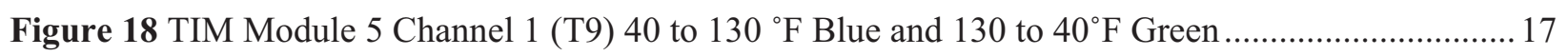

Figure 19 AIM Module 2 Channels DP1 to 4 Time vs. Temp vs. Volts................................................. 17

Figure 20 AOM Module 6 Channels A1 to 4 Time vs. Temp vs. mA …................................................. 18

Figure 21 TIM Modules 3,4 and 5 Time vs. Chamber Temp vs. Sensor Temp...................................... 18

Figure 22 Standard Deviation vs. Temperature *manufactures specifications ........................................20

Figure 23 Frequency Distribution of all test results according to Channel output range..........................22

Figure 24 Frequency Distribution of all test results versus baseline data according to channel...............23

Figure 25 Standard Deviation by Channel by Chamber Temperature by Test ....................................... 24

\section{TABLES}

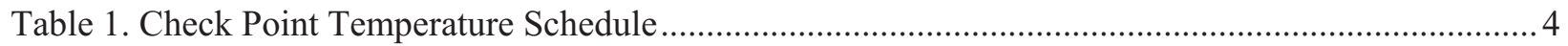

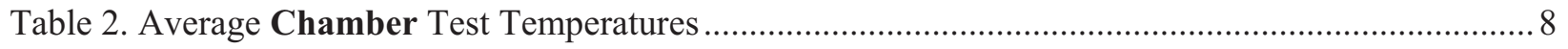

Table 3 Voltage input measurements AIM Module 2 DP1-4 ............................................................ 8

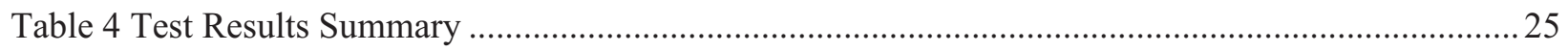

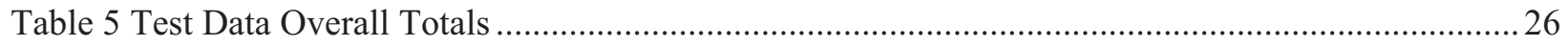

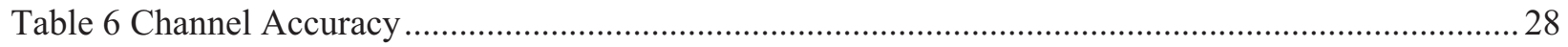

\section{ACRONYMS}




\section{Water Power Calculator Temperature and Analog input/output Module Ambient Temperature Testing}

A series of three ambient temperature tests were conducted for the Water Power Calculator development using the INL Calibration Laboratory's Tenney Environmental Chamber. The ambient temperature test results demonstrate that the Moore Industries Temperature Input Modules, Analog Input Module and Analog Output Module, ambient temperature response meet or exceed the manufactures specifications

\section{Scope}

Establish the ambient working temperature for the Moore Industries Temperature Input Module and Analog Input Modules (AIM) for the preliminary design of the ATR Water Power Calculator. For the purposes of this test, "ambient working temperature" is defined as the maximum and minimum expected ambient temperatures for the ATR building, ranging from $\sim 130^{\circ} \mathrm{F}$ to $\sim 40^{\circ} \mathrm{F}$. This test was undertaken to confirm correctness of assumptions used in Engineering Calculations and Analysis Report (ECAR) -1344, "Uncertainty Analysis for 2011 ATR Water Power Calculator Upgrade" with respect to contribution of ambient temperature variations to Water Power Calculator uncertainty". This work was performed at CFA 698 INL Calibration Laboratory under CWI-3541. This document serves as both Test procedure and Test results.

\section{Test Description}

\subsection{Test Equipment \& Description}

\begin{tabular}{|l|l|l||}
\hline \multicolumn{1}{|c|}{ Unit Under Test Characteristics } & \multicolumn{1}{|c||}{ Performance Specifications } & \multicolumn{1}{|c|}{ Test Method } \\
\hline \hline Water Power Calculator system (Moore Ind. & Range: $40^{\circ} \mathrm{F}\left(4.44^{\circ} \mathrm{C}\right)$ to & $\begin{array}{l}\text { Compared with an } \\
\text { accurate standard } \\
\text { Analog Input Module (AIM), Analog Output }\end{array}$ \\
Module (AOM), Temperature Input Module & $130^{\circ} \mathrm{F}\left(54.44^{\circ} \mathrm{C}\right)$ & $\begin{array}{l}\text { chamber } \\
\text { char in }\end{array}$ \\
& Accuracy: & \\
& TIM: $+/-0.005^{\circ} \mathrm{C} /{ }^{\circ} \mathrm{C}$ Change & \\
& AOM: $+/-0.01 \%$ of $\max$ span $/{ }^{\circ} \mathrm{C}$ & \\
& AIM: $+/-0.01 \%$ of max span $/{ }^{\circ} \mathrm{C}$ & \\
\hline
\end{tabular}

\section{2}

The setup for this test is to measure the effects of ambient temperature changes on the Moore Ind. modules directly and not on the instruments read by the modules. Twelve data channels were prepared to simulate the expected data types for the Water Power Calculator data acquisition. These channel inputs, hereafter called a "sensor terminal block", provide a constant steady state source for data from which to gauge the impact of temperature changes have on the modules. Only the modules, and their necessary components are to be placed in the environmental chamber, while the other components, including the sensor terminal block, are maintained at a steady room temperature. The Tenney Environmental Chamber was used to vary the ambient 
temperature for the modules to a series of temperatures representative of ambient temperature extremes that might occur in the ATR facility. Temperature changes (adjustments) will initiate at a temperature of $40^{\circ} \mathrm{F}\left(4.44^{\circ} \mathrm{C}\right)$ and stepped in $15^{\circ} \mathrm{F}$ steps to the highest temperature of $130^{\circ} \mathrm{F}\left(54.44^{\circ} \mathrm{C}\right)$ as outlined below in Table 1 , as closely as possible. Each temperature is to be held for a period of 2 hours to assure temperature stability was reached within the modules. The chamber is then stepped back down to $40^{\circ} \mathrm{F}$ and then repeated two more time, for a total of three cycles.

\section{EQUIPMENT REQUIRED FOR TEST}

\begin{tabular}{|ll|c|l||}
\hline \hline Nomenclature & \multicolumn{1}{c|}{$\begin{array}{c}\text { Minimum Use } \\
\text { Specifications }\end{array}$} & \multicolumn{1}{c|}{$\begin{array}{c}\text { Recommended } \\
\text { Equipment }\end{array}$} \\
\hline \hline 3.1 & Temperature Chamber & Range: As specified & $\begin{array}{l}\text { Tenney } \\
\text { T30RC-2 }\end{array}$ \\
\hline 3.2 & Standard Thermometer(s) & Range: As specified & $\begin{array}{l}\text { Hart Scientific Chub E-4 w/probe } \\
\text { Burns Engineering Platinum } \\
\text { Resistance Thermometer }\end{array}$ \\
\hline
\end{tabular}

NOTE : If the instrument listed does not meet the 4:1 test uncertainty ratios (TUR) for at least one test point. These points will be identified by an "*” in the minimum use specification column.

\section{PRELIMINARY OPERATIONS}

\subsection{Hazard Mitigation}

4.1.1 The operation of the Tenney Environmental Chamber and any Calibration Laboratory Equipment is RESTRICTED to Qualified Standards and Calibration Laboratory (S\&CL) Calibration Technicians trained to the hazards and the hazard controls identified by LI-13476, "Standards and Calibration Laboratory Hazard Identification and Mitigation."

4.1.2 Place the unit under test (UUT) and standard thermometer within close proximity of each other (3.2) inside the Temperature Chamber (3.1).

\section{TEST}

NOTE: The Tenney Environmental Chamber does not require calibration when chamber temperature is measured by a calibrated instrument.

\subsection{Calibrated Instrumentation}

5.1.1 The following equipment was used for this test:

\begin{tabular}{|l|l|l|}
\hline Equipment Name & Property Number & Calibration Due Date \\
\hline $\begin{array}{l}\text { Internal PRT - Burns Engineering } \\
\text { Platinum Resistance Thermometer }\end{array}$ & 714273 & $3 / 25 / 2011$ \\
\hline
\end{tabular}




\begin{tabular}{|l|l|l|}
\hline $\begin{array}{l}\text { External PRT - Burns Engineering } \\
\text { Platinum Resistance Thermometer }\end{array}$ & 712788 & $3 / 24 / 2011$ \\
\hline $\begin{array}{l}\text { Thermometer Readout - Hart Scientific } \\
1529 \text { Chub-E4 Standards Thermometer }\end{array}$ & 720479 & $1 / 11 / 2012$ \\
\hline $\begin{array}{l}\text { Voltmeter - Agilent 34401 Digital } \\
\text { Multimeter }\end{array}$ & 718418 & $4 / 20 / 2011$ \\
\hline
\end{tabular}

\section{$5.2 \quad$ UUT Setup}

NOTE: the following steps are to be completed by the UUT equipment engineers

5.2.1 Setup the UUT equipment in the Chamber and make necessary connections.

5.2.2 Connect UUT to the Water Power Calculator Data Recorder (Honeywell Multitrend SX).

5.2.3 Program to the Water Power Calculator Data Recorder to record data once every 20 seconds for each channel (pen) for each of the AIM, AOM and TIM modules.

5.2.4 Synchronize the Honeywell SX data recorder time with the computer recording the test chamber data. This can be done by using the built in NTP server or by manually setting the Recorder clock to match the test chamber's clock.

\subsection{Temperature Measurement.}

5.3.1 Perform a 37-point check of the applicable UUT temperature range. Set the temperature chamber to the first temperature checkpoint.

5.3.2 Allow adequate time for chamber and instrument stabilization.

5.3.3 Using the Standard Thermometer (3.2), verify that the UUT reads within the stated accuracy given in Appendix A.

5.3.4 Record the Analog input voltage levels prior to the start of each test.

5.3.5 Repeat Steps 5.1.2 and 5.1.3 for the remaining checkpoints as detailed in Table 1 below.

5.3.6 If necessary Repeat Steps 5.1.1 to 5.1.4 to achieve the three consecutive tests.

NOTE: For maximum-minimum thermometers, note that maximumminimum indications are within manufacturer's specs. 
5.3.7 Disconnect and secure all equipment.

\subsection{If the UUT has humidity measurement capabilities, calibrate using S\&CL CWI-3066.}

\subsection{Collect the following at 20 sec intervals,}

5.5.1 Time

5.5.2 Chamber Temperature

5.5.3 Laboratory Ambient Temperature, with temperature probe with in one to two inches of the test subject terminal block.

5.5.4 Chamber percent relative humidity $(\% \mathrm{RH})$.

\subsection{Turn Temperature Chamber (3.1) off and allow the inside temperature to cool to a safe temperature.}

Table 1. Check Point Temperature Schedule

\begin{tabular}{|c|c|c|c|c|c|c|c|c|c|}
\hline Check Point & Time & Temperature ${ }^{\circ} \mathrm{F}$ & Check Point & Time & Temperature ${ }^{\circ} \mathrm{F}$ & Check Point $^{\text {Time }}$ & Temperature $^{\circ} \mathrm{F}$ \\
\hline 1 & 12 & 40 & 13 & 12 & 40 & 25 & 12 & 40 \\
\hline 2 & 14 & 55 & 14 & 14 & 55 & 26 & 14 & 55 \\
\hline 3 & 16 & 70 & 15 & 16 & 70 & 27 & 16 & 70 \\
\hline 4 & 18 & 85 & 16 & 18 & 85 & 28 & 18 & 85 \\
\hline 5 & 20 & 100 & 17 & 20 & 100 & 29 & 20 & 100 \\
\hline 6 & 22 & 115 & 18 & 22 & 115 & 30 & 22 & 115 \\
\hline 7 & 00 & 130 & 19 & 00 & 130 & 31 & 00 & 130 \\
\hline 8 & 02 & 115 & 20 & 02 & 115 & 32 & 02 & 115 \\
\hline 9 & 04 & 100 & 21 & 04 & 100 & 33 & 04 & 100 \\
\hline 10 & 06 & 85 & 22 & 06 & 85 & 34 & 06 & 85 \\
\hline 11 & 08 & 70 & 23 & 08 & 70 & 35 & 08 & 70 \\
\hline 12 & 10 & 55 & 24 & 10 & 55 & 36 & 10 & 55 \\
\hline
\end{tabular}

\section{$5.7 \quad$ Test Setup}

Testing started on January $31^{\text {st }} 2011$ at approximately $12: 50 \mathrm{pm}$ and ran to approximately

16:20pm Friday February 4 2011. Testing was performed in the CFA-698 INL

Calibration laboratory using the Tenney T30RC-2 environmental chamber. 

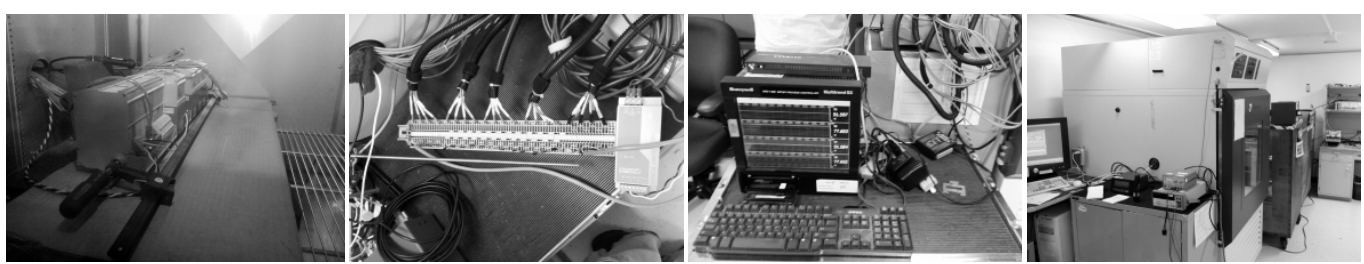

Figure 1 Test equipment and Tenney Chamber (from left to right, Moore modules, sensor terminal block, Honeywell recorder, Tenney Chamber)

The Moore Industries microNCS provides a real-time signal gateway between the AIM, AOM, and TIMs. The microNCS "concentrates" data from the AIM, AOM and the TIMs into one communication links, and transmits it to Honeywell controller. The Honeywell was used to record all the data channels (4) from each of the AIM, AOM and TIM modules, 20 channels total. The microNCS, one Analog Input Module (AIM), one Analog Output Module (AOM) and three Temperature Input Modules (TIM) were placed in the environmental chamber.

The following key is used to correlate the channels to the Moore modules.

\begin{tabular}{|c|c|}
\hline AIM MOD 2 Channel $1=\mathrm{DP} 1$ Volts & TIM MOD 3 Channel $1=\mathrm{T} 1{ }^{\circ} \mathrm{C}$ \\
\hline AIM MOD 2 Channel $2=\mathrm{DP} 2$ Volts & TIM MOD 3 Channel $2=\mathrm{T} 2{ }^{\circ} \mathrm{C}$ \\
\hline AIM MOD 2 Channel $3=\mathrm{DP} 3$ Volts & TIM MOD 3 Channel $3=\mathrm{T} 3{ }^{\circ} \mathrm{C}$ \\
\hline AIM MOD 2 Channel $4=\mathrm{DP} 4$ Volts & TIM MOD 3 Channel $4=\mathrm{T} 4{ }^{\circ} \mathrm{C}$ \\
\hline AOM MOD 6 Channel $1=\mathrm{A} 1 \mathrm{~mA}$ & $\mathrm{TIM}$ MOD 4 Channel $1=\mathrm{T} 5{ }^{\circ} \mathrm{C}$ \\
\hline AOM MOD 6 Channel $2=\mathrm{A} 2 \mathrm{~mA}$ & $\mathrm{TIM}$ MOD 4 Channel $2=\mathrm{T} 6{ }^{\circ} \mathrm{C}$ \\
\hline AOM MOD 6 Channel $3=\mathrm{A} 3 \mathrm{~mA}$ & $\mathrm{TIM}$ MOD 4 Channel $3=\mathrm{T} 7{ }^{\circ} \mathrm{C}$ \\
\hline AOM MOD 6 Channel $4=\mathrm{A} 4 \mathrm{~mA}$ & $\mathrm{TIM}$ MOD 4 Channel $4=\mathrm{T} 8{ }^{\circ} \mathrm{C}$ \\
\hline & $\mathrm{TIM}$ MOD 5 Channel $1=\mathrm{T} 9{ }^{\circ} \mathrm{C}$ \\
\hline & $\mathrm{TIM}$ MOD 5 Channel $2=\mathrm{T} 10{ }^{\circ} \mathrm{C}$ \\
\hline & $\mathrm{TIM}$ MOD 5 Channel $3=\mathrm{T} 11{ }^{\circ} \mathrm{C}$ \\
\hline & $\mathrm{TIM}$ MOD 5 Channel $4=\mathrm{T} 12{ }^{\circ} \mathrm{C}$ \\
\hline
\end{tabular}

See Figures 2 and 3 for wiring layout and connections.

Connected to each of the Moore modules was a terminal block, which served as the connection point for the inputs and outputs. Constant Resistors were used to simulate temperature probes, a calibrated voltage source was used to provide a constant voltage input and the recorder was use to provide a constant current. The constant resistors varied from 110 to $140 \Omega$ s. The sensor terminal block was placed outside of the 
chamber. The Honeywell recorder was also placed outside the chamber. This was to provide a steady state condition for the input/outputs to minimize any variability in the input or output.

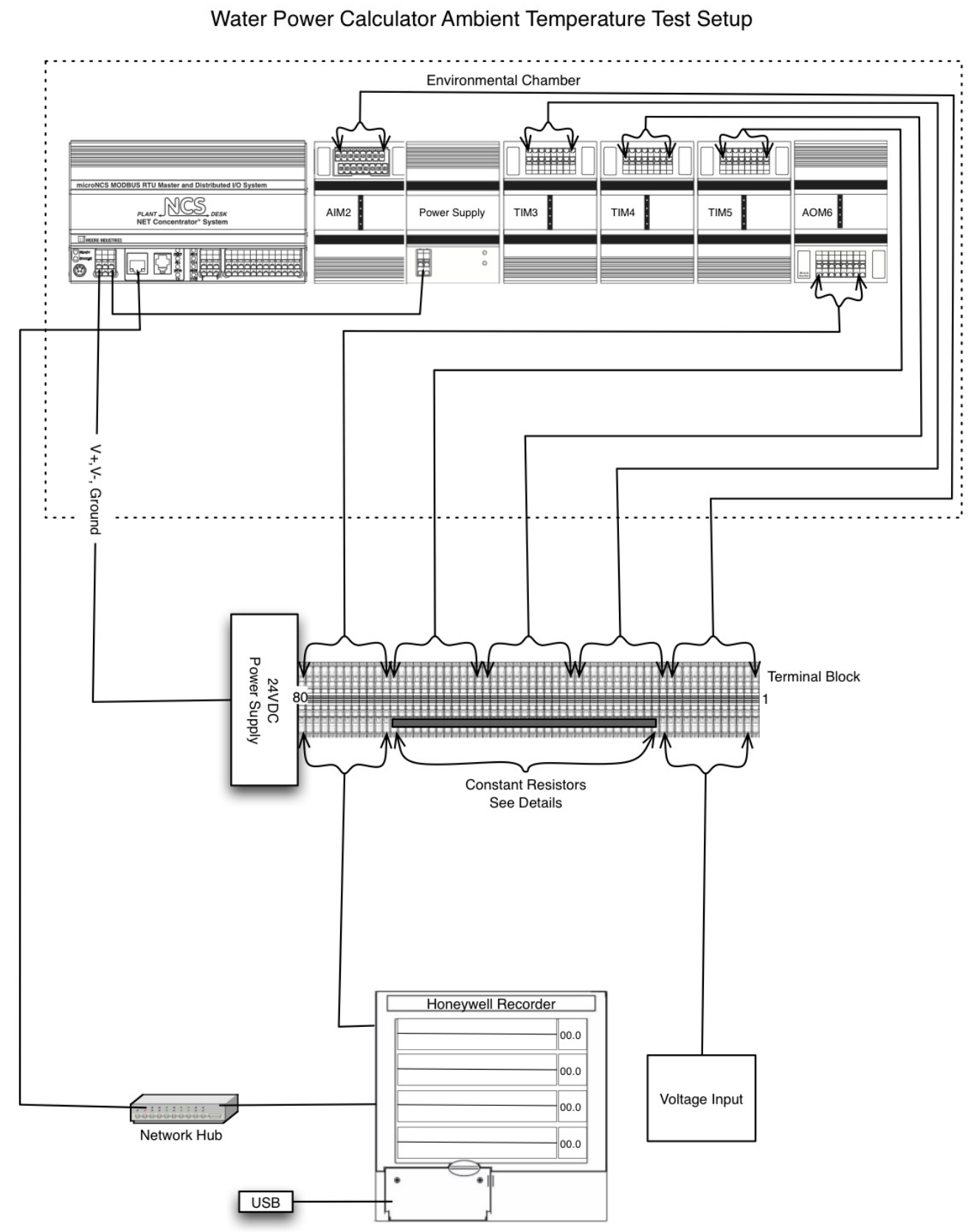

Note: Data transfer to
PC Latop via USB Drive

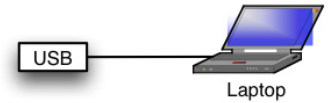

Figure 2 Test Setup 


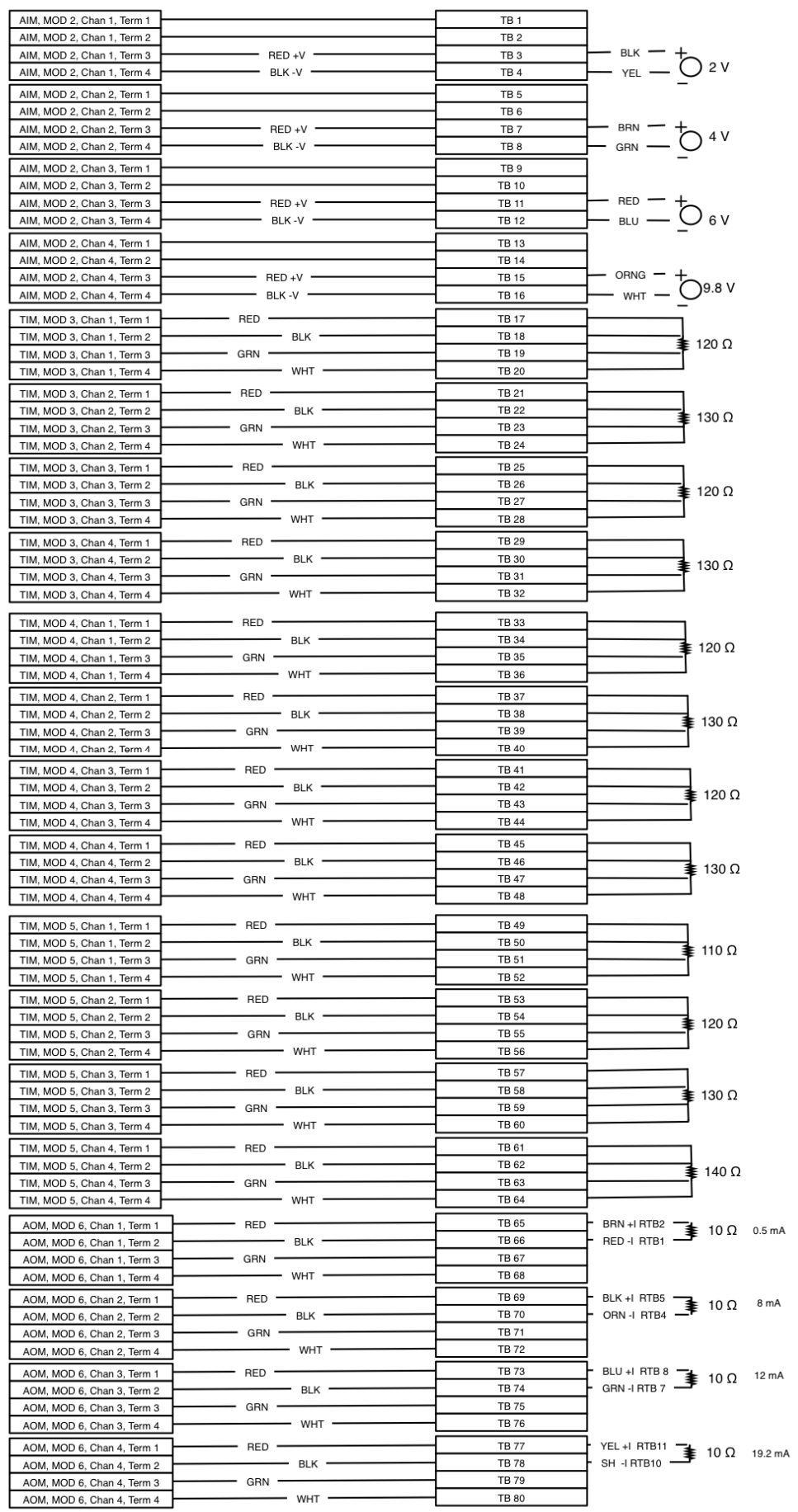

\section{Figure 3 Test Setup Connections}




\section{TEST RESULTS}

\subsection{Results}

Three separate tests were conducted, however data logging by the Honeywell recorder records the data as one single "data strip chart". The data is saved to a Honeywell proprietary data file and requires their software to "export" data into a comma separated values (CSV) file. For simplicity and assurity of testing, the recorder was set to continuously record from the start of test 1 to the end of test 3 . At the end of each test, a backup copy of the data was created. Some of plots show in the following figures show all three tests in one plot. The Tenney environmental chamber was programmed according to values in table 1 , however the actual temperatures measured next to the equipment varied slightly. Table 2 shows the average temperatures.

Table 2. Average Chamber Test Temperatures

\begin{tabular}{|c|l|l|l|l|l|l|l|l|}
\hline Check Point & Time & Temperature ${ }^{\circ} \mathrm{F}$ & Check Point & Time & Temperature ${ }^{\circ} \mathrm{F}$ & Check Point & Time & Temperature ${ }^{\circ} \mathrm{F}$ \\
\hline 1 & $12: 20$ & 41.83782527 & 13 & $14: 06$ & 41.85951 & 25 & $14: 20$ & 41.91438056 \\
\hline 2 & $14: 20$ & 56.37938352 & 14 & $16: 06$ & 56.30566243 & 26 & $16: 20$ & 56.35362044 \\
\hline 3 & $16: 20$ & 70.92456087 & 15 & $18: 06$ & 70.86315856 & 27 & $18: 20$ & 70.89215304 \\
\hline 4 & $18: 20$ & 85.52067692 & 16 & $20: 06$ & 85.4431221 & 28 & $20: 20$ & 85.4509674 \\
\hline 5 & $20: 20$ & 100.0022011 & 17 & $22: 06$ & 99.88893536 & 29 & $22: 20$ & 99.92003444 \\
\hline 6 & $22: 20$ & 114.4938132 & 18 & $00: 06$ & 114.3671713 & 30 & $00: 20$ & 114.3413702 \\
\hline 7 & $00: 20$ & 128.9245714 & 19 & $02: 06$ & 128.8523444 & 31 & $02: 20$ & 128.8475635 \\
\hline 8 & $02: 20$ & 114.6699333 & 20 & $04: 06$ & 114.5728011 & 32 & $04: 20$ & 114.5542155 \\
\hline 9 & $04: 20$ & 100.2014176 & 21 & $06: 06$ & 100.1189 & 33 & $06: 20$ & 100.1151492 \\
\hline 10 & $06: 20$ & 85.72106111 & 22 & $08: 06$ & 85.65997514 & 34 & $08: 20$ & 85.68167514 \\
\hline 11 & $08: 20$ & 71.13628315 & 23 & $10: 06$ & 71.10359558 & 35 & $10: 20$ & 71.12970608 \\
\hline 12 & $10: 20$ & 56.53626044 & 24 & $12: 06$ & 56.5288989 & 36 & $12: 20$ & 56.57720611 \\
\hline $12 \mathrm{~B}$ & $12: 20$ & 41.943078 & $24 \mathrm{~B}$ & $14: 06$ & 41.9143806 & 37 & $14: 20$ & 41.97118453 \\
\hline
\end{tabular}

Note: because of the way the Tenney chamber is programmed a $12 \mathrm{~B}$ and $24 \mathrm{~B}$ was added to instruct the chamber to start the $40{ }^{\circ} \mathrm{F}$ cool cycle prior to starting the next test. The chamber was held at each temperature for two hours to allow each module's temperature to stabilize.

Voltage input were measured at the start of each test and are provided below in Table 3

Table 3 Voltage input measurements AIM Module 2 DP1-4

\begin{tabular}{|l|l|l|l|l|l|}
\hline Test 1 & & Test 2 & & Test 3 & \\
\hline Channel 1 & 1.9994 & Channel 1 & 1.9997 & Channel 1 & 1.9994 \\
\hline Channel 2 & 3.9997 & Channel 2 & 3.9998 & Channel 2 & 3.9998 \\
\hline
\end{tabular}




\begin{tabular}{|c|c|c|c|c|c|}
\hline Channel 3 & 5.9999 & Channel 3 & 6.0000 & Channel 3 & 6.0000 \\
\hline Channel 4 & 9.7997 & Channel 4 & 9.7998 & Channel 4 & 9.7999 \\
& & & & & \\
\hline
\end{tabular}

Figures 4 through 21 show the test results for the three tests, some of the plots list the total time in "epoch time" (seconds starting from Jan 1, 1970 UTC). Because of the large amount of data collected, Matlab was used to generate some of these figures. The plotting function displays the date and time in seconds.

The tests were designed to determine the ambient operating temperature of the Moore modules, the effects of temperature, or more importantly the change of temperature on the data collected buy the modules and the accuracy of those measurements.

Figures 4 to 6 show the data as collected by the strip chart for channels prior to the test to "baseline" the data. The baseline data was collected at an ambient temperature of approximately $70{ }^{\circ} \mathrm{F}$, where both the input terminal block and the modules are at the same temperature. The TIMs out put is in degrees Celsius calculated from a ration of the voltage across the constant resistor for each channel (see Figure 3 above).
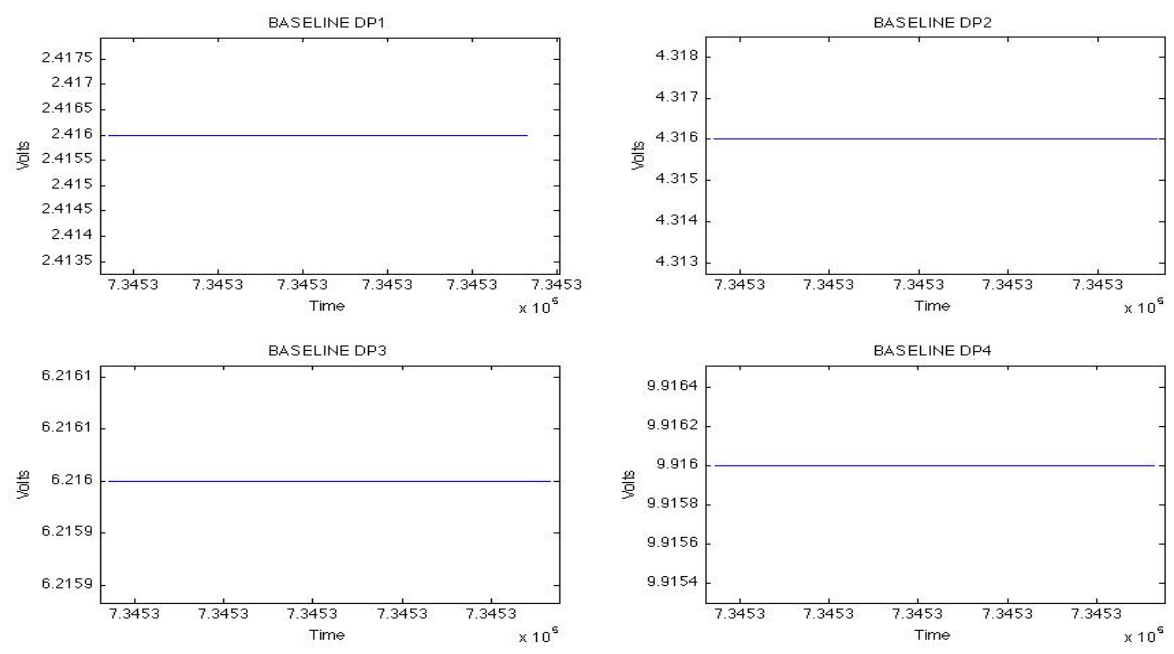

Figure 4 AIM Baseline 

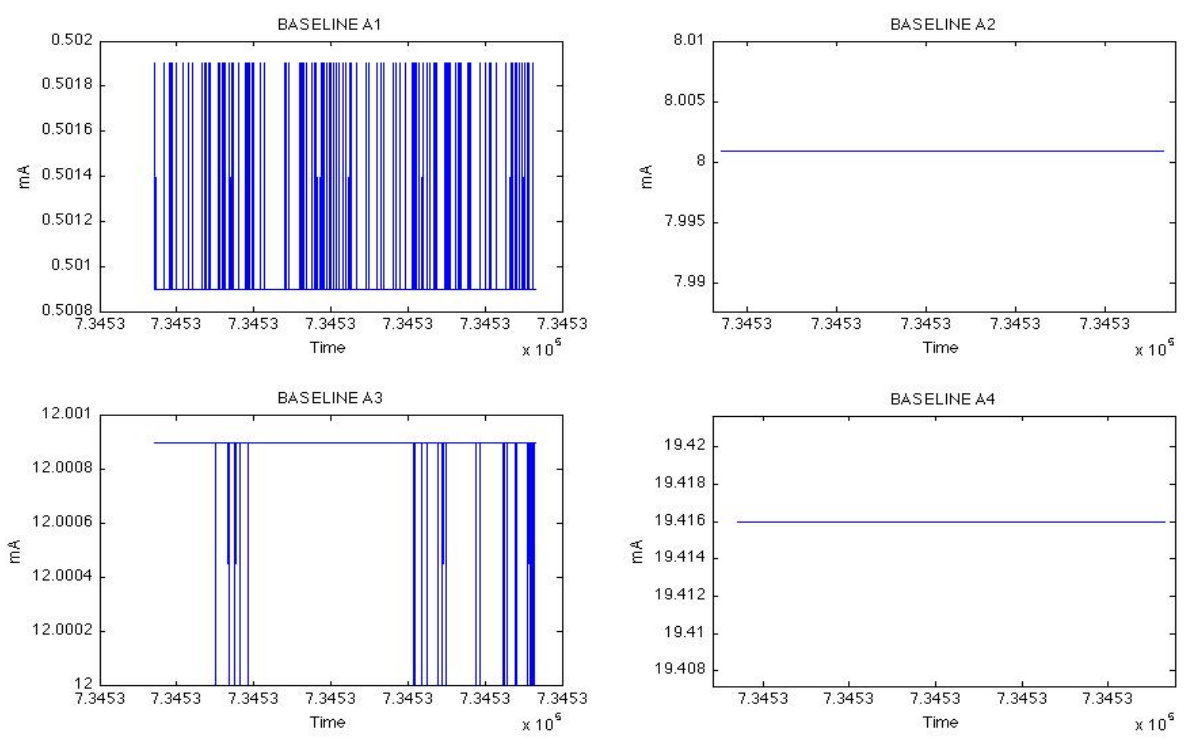

Figure 5 AOM Baseline
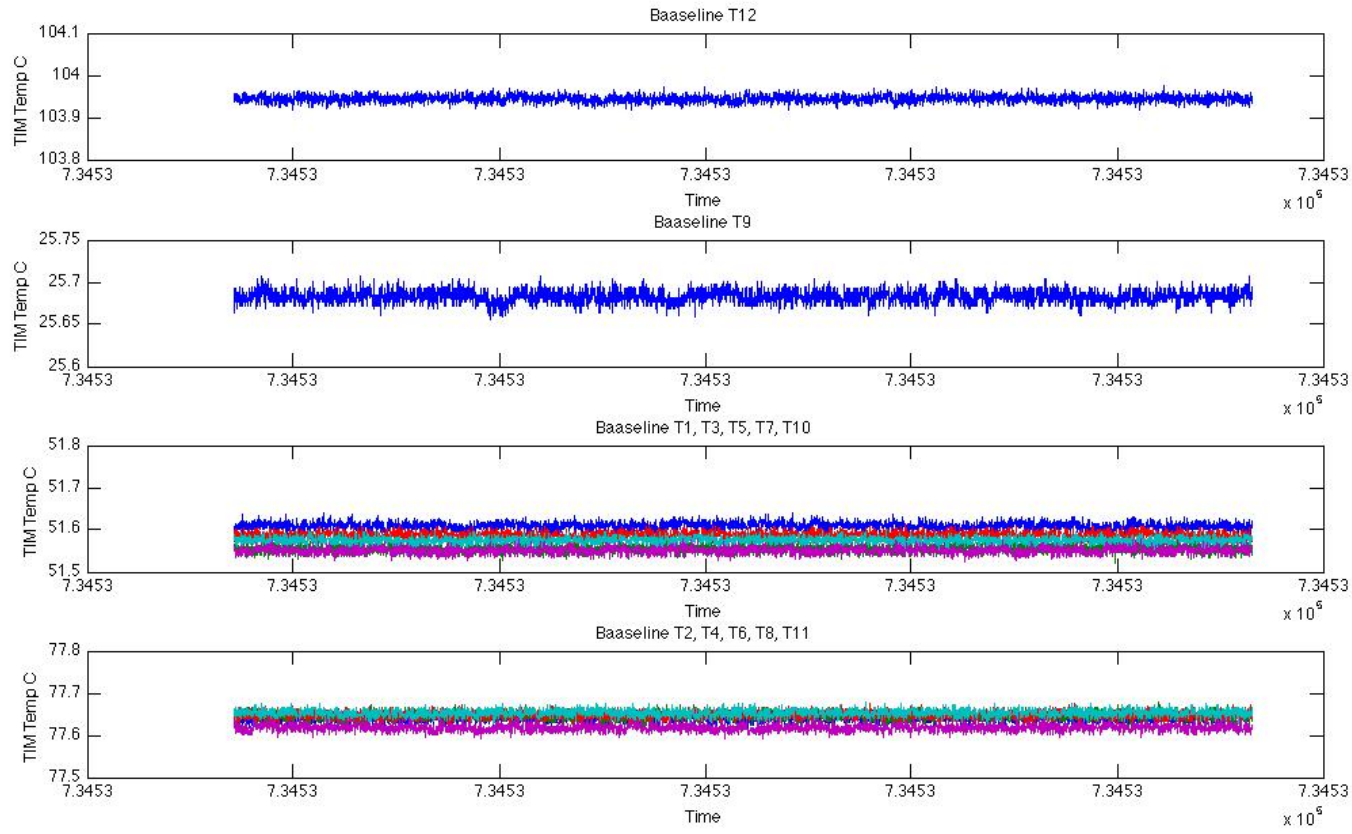

Figure 6 TIM Baseline

Figure 7 shows test results as collected by the Honeywell in "strip chart" format for all channels. The data was collected chamber temperatures ranging from approximately 40 ${ }^{\circ} \mathrm{F}$ to $130{ }^{\circ} \mathrm{F}$ and back down to $40{ }^{\circ} \mathrm{F}$, with the Moore modules in the chamber and the input terminal block at laboratory ambient temperature. The output of the modules 


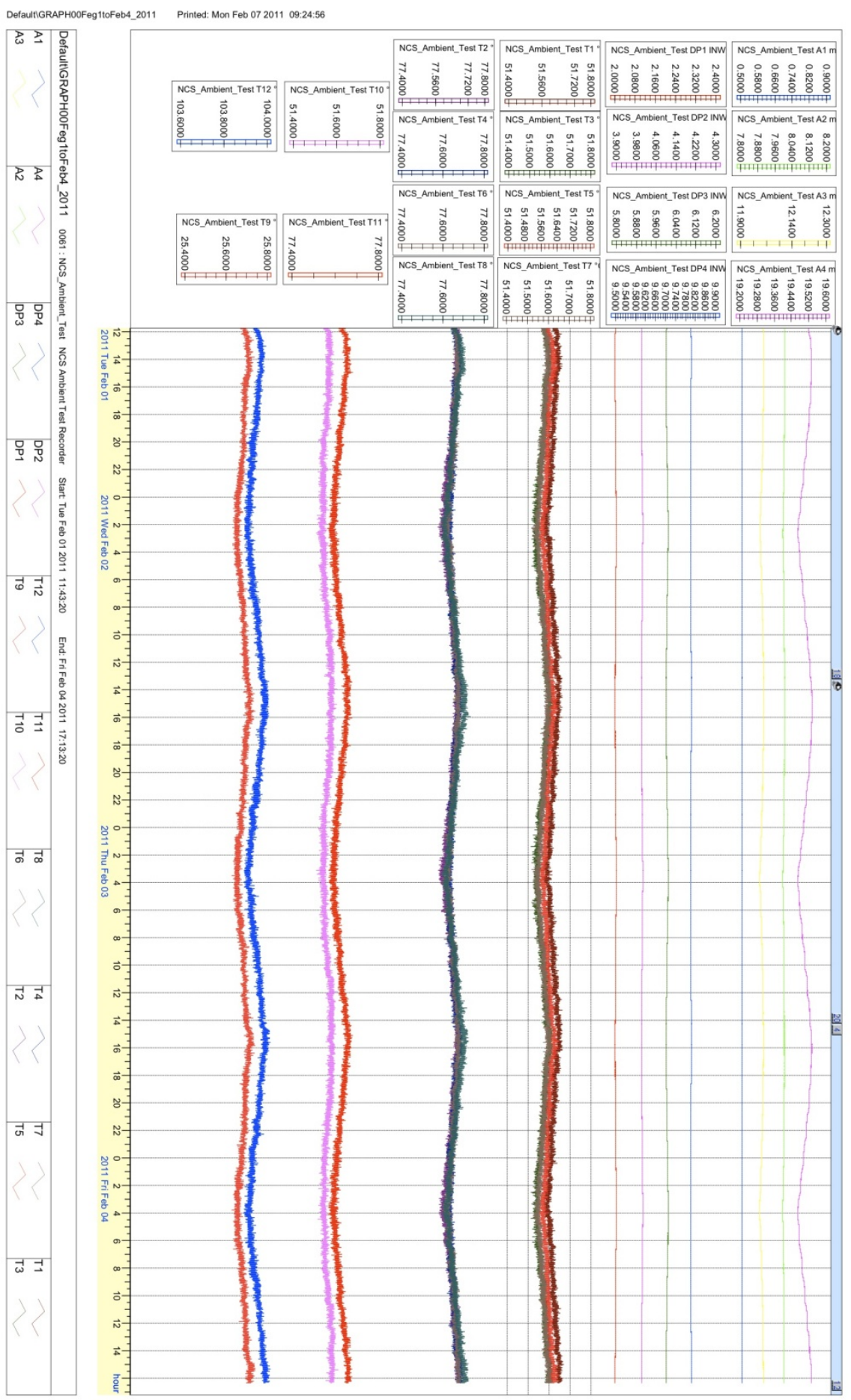

Figure 7 Strip Chart Recorder of Tests 1,2 and 3

Figure 8 and 9 show the ambient and chamber temperature plots. 


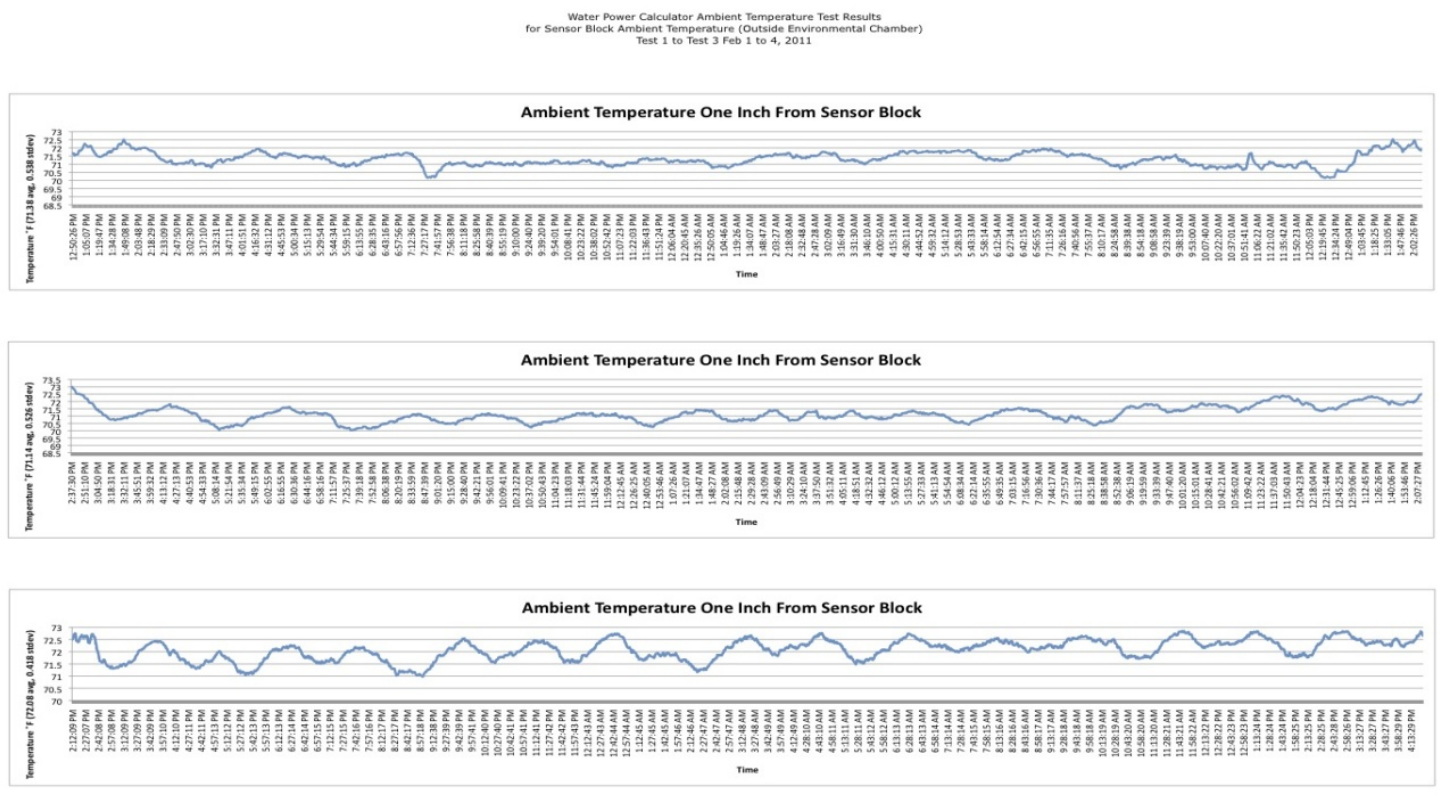

Figure 8 Ambient Laboratory Temperature (outside of chamber)

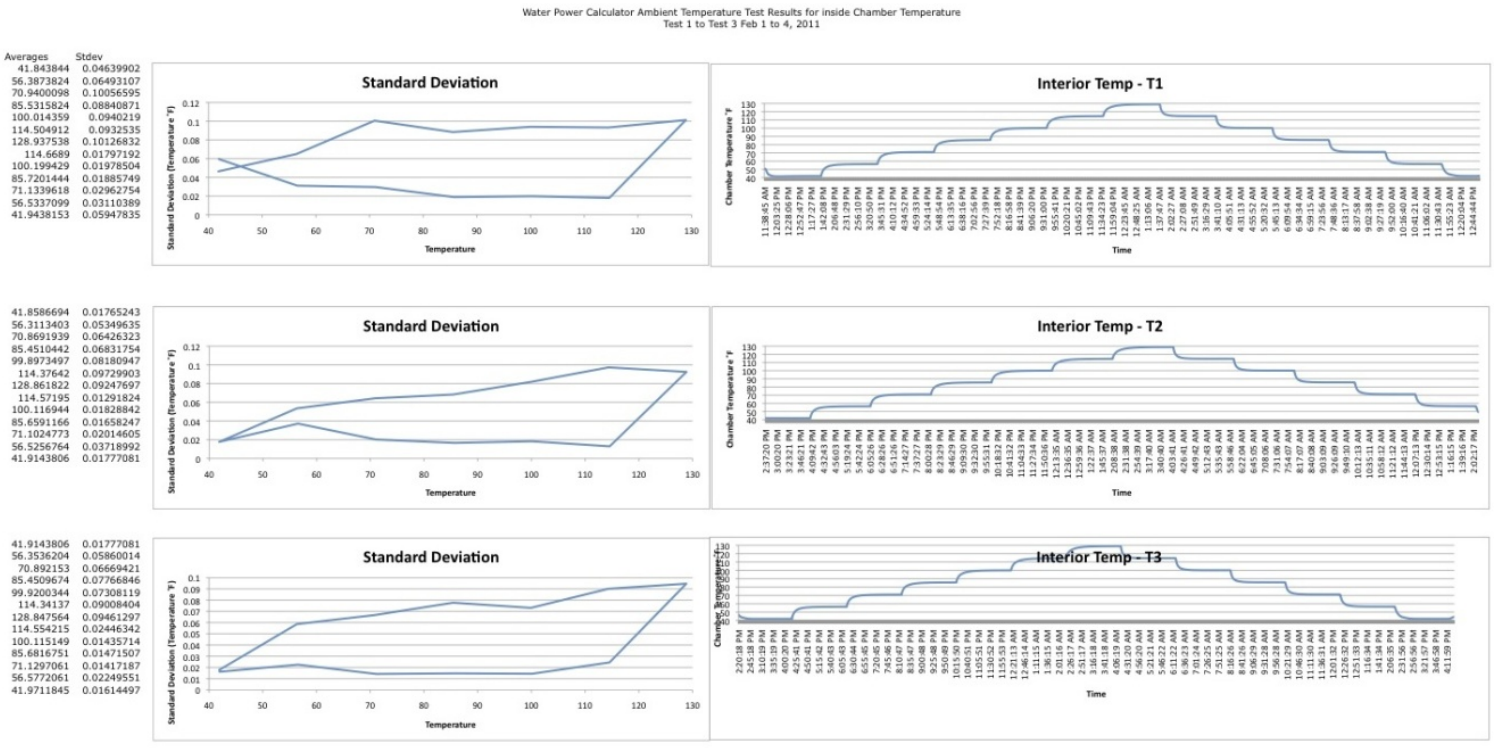

Figure 9 Chamber Temperatures Test 1, 2 and 3 (T1, T2, and T3)

The Tenney environmental chamber could not hold the \% Relative Humidity to a specified value. Therefore it was determined it would be best to set the chamber to as dry as possible. Figure 10 show the plot of the $\%$ RH for the three Tests. 


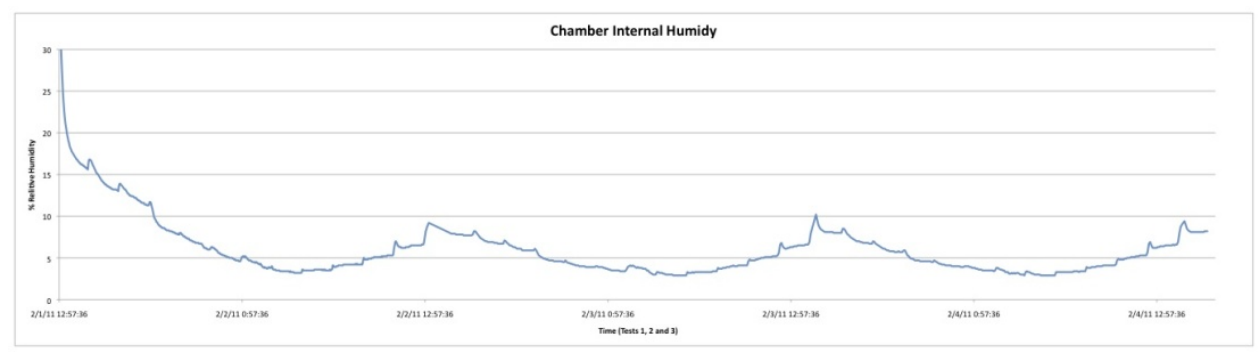

Figure $10 \%$ Relative Humidity vs. Time inside of the Chamber.

Figures 11 to 14 show data of each channel vs. time for all three tests.
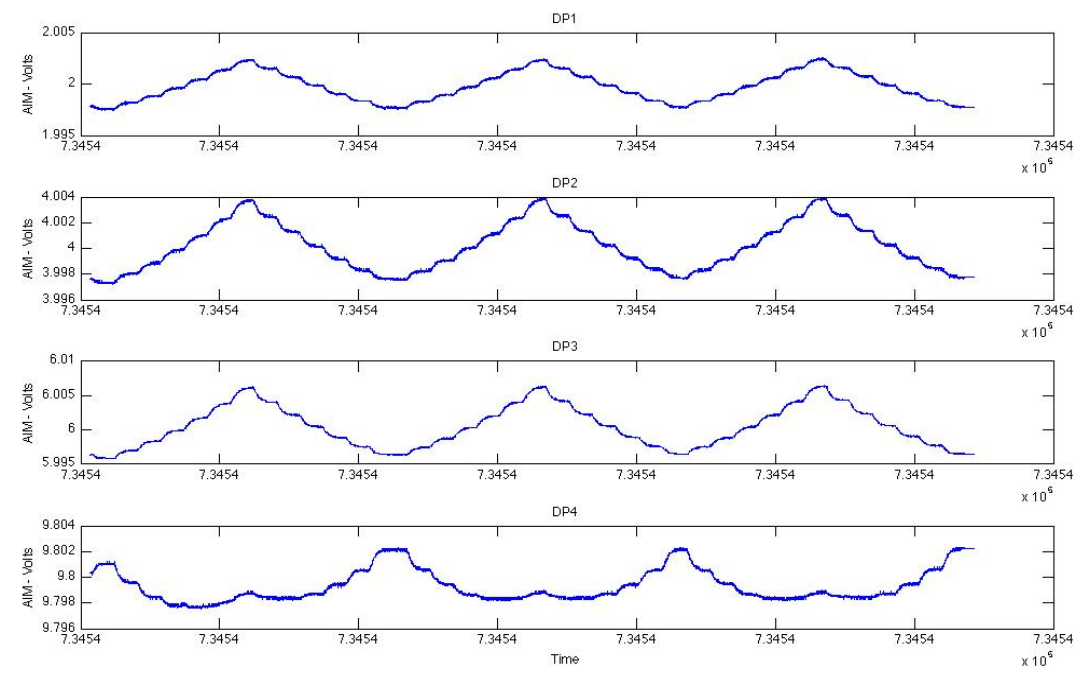

Figure 11 AIM module 2 Channels 1 to 4
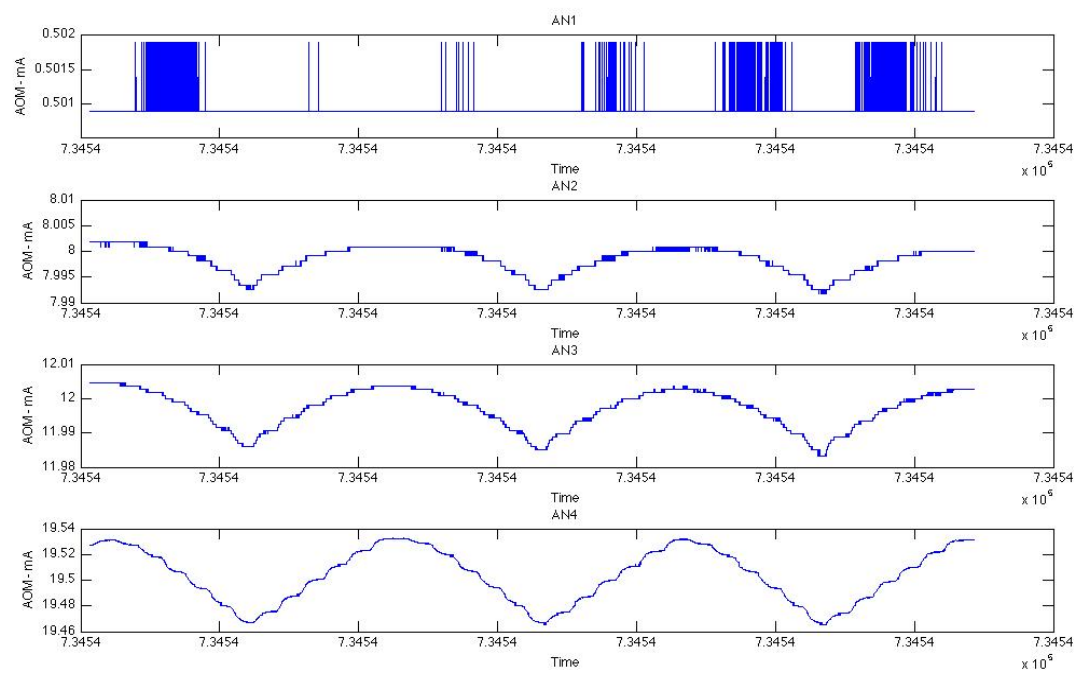

Figure 12 AOM module 6 channels 1 to 4 

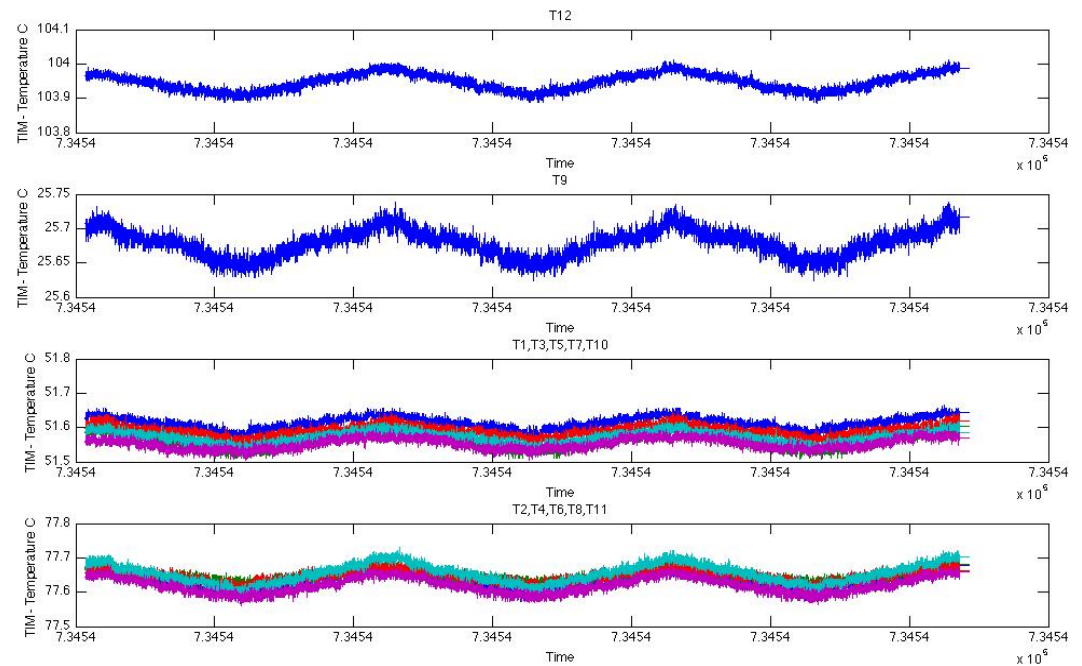

Figure 13 modules TIM3, 4 and 5 grouped by sensor output.
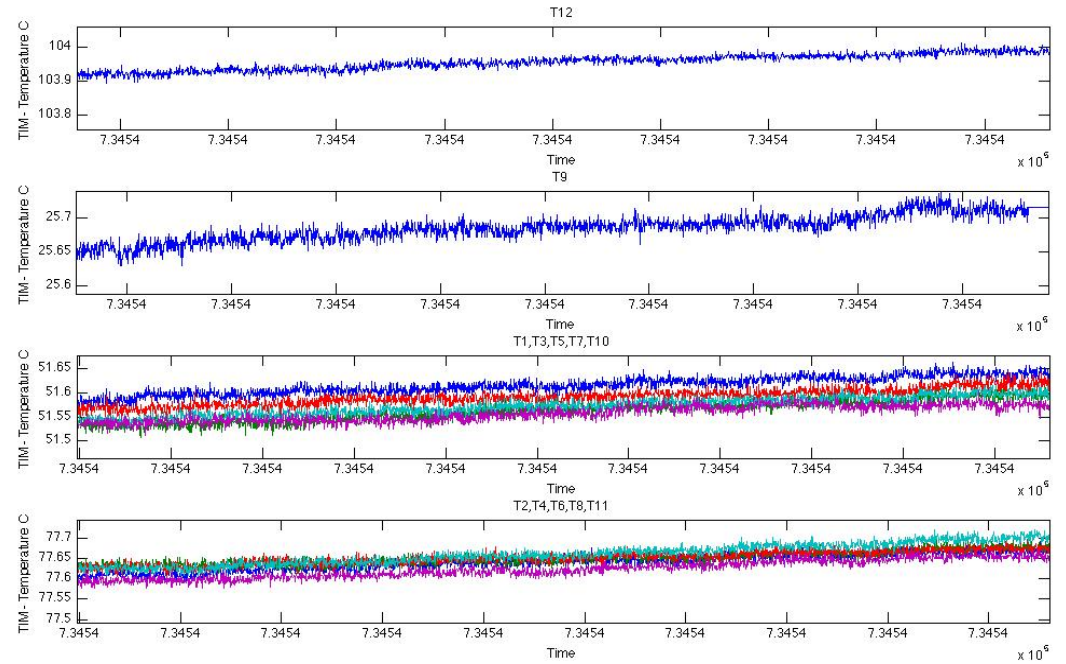

Figure 14 Zoomed view of Figure 13 for the last half of Test 3

Each of the plots in Figures 11 to 14 shows data from all three tests, It can be seen that the changing of chamber temperature does have an effect on teach of the channels and that the results are repetitive. Channels DP1 to DP3 show an increase of volts with an increase of temperature. Channel DP4 showed the opposite, a decrease of voltage with increasing temperature. Channel A2 to A4 show a decrease in current with increasing temperature while the change in Channel A1 appears to small to draw any conclusions. 
Figures 15 to 17 show the plot of data collected vs. the temperature for each of the channels, grouped by type of module and range of input.
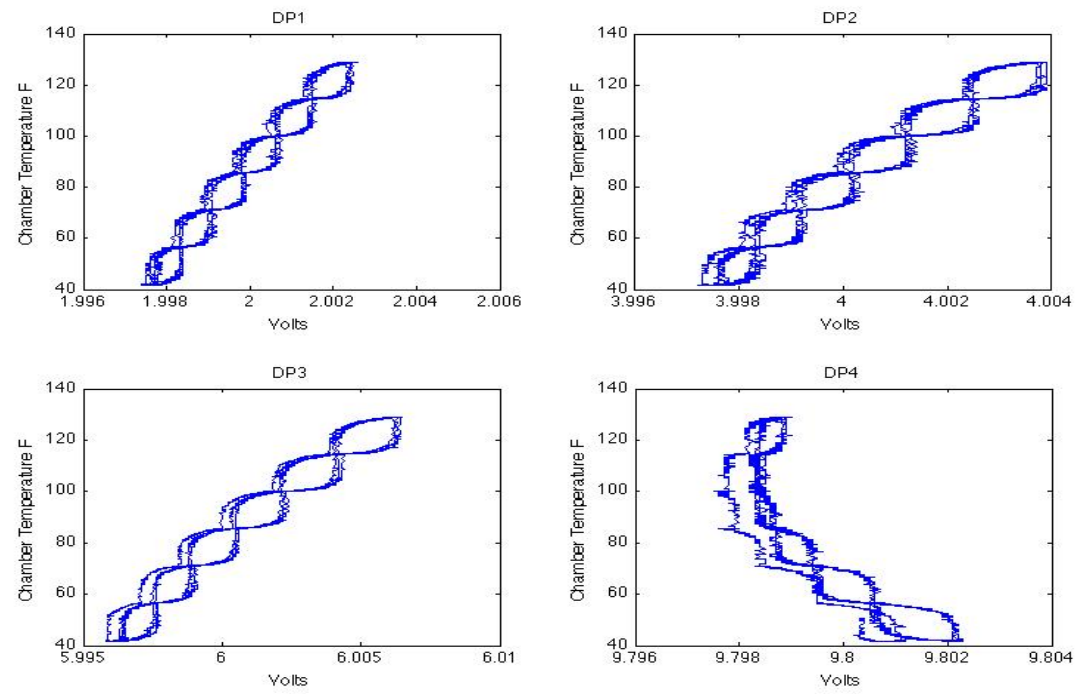

Figure 15 AIM Module 2 Channels 1 to 4 Temperature vs. Time
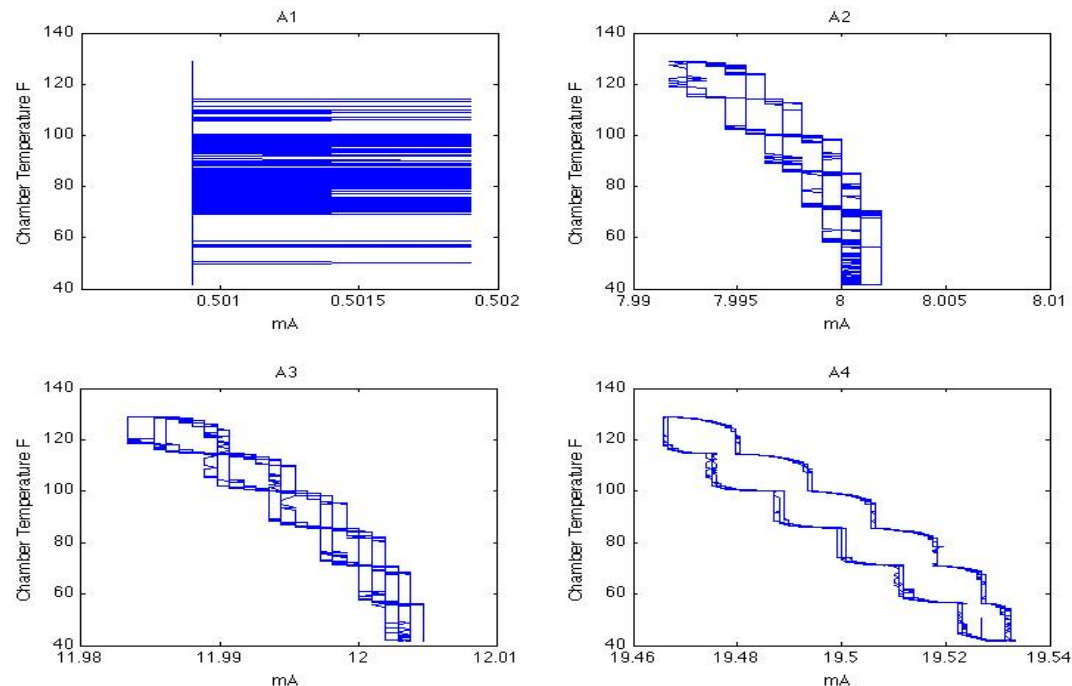

Figure 16 AOM Module 6 Channels 1 to 4 Temperature vs. Time 

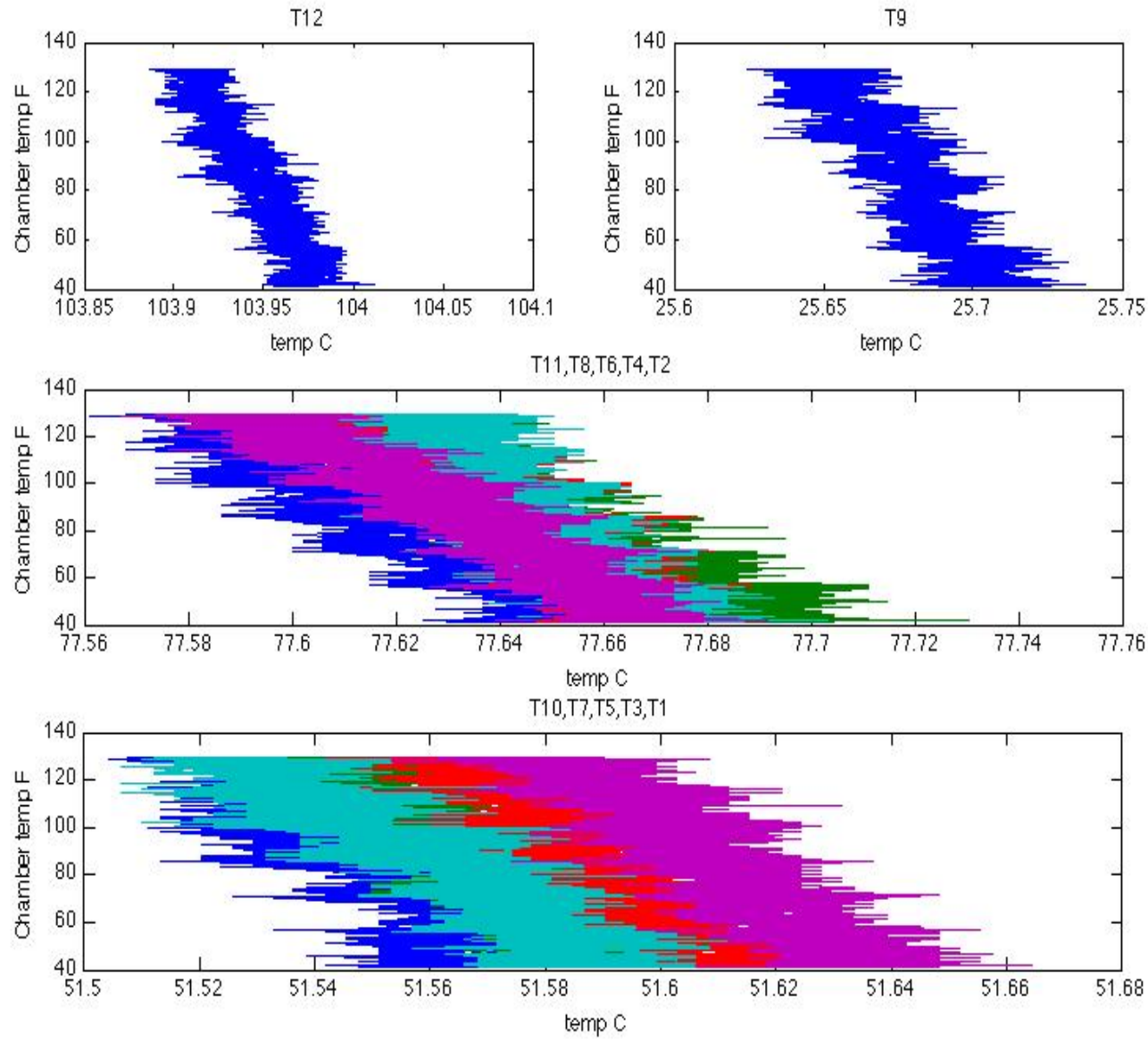

Figure 17 TIM Modules 3,4, and 5 Channels 1 to 4 Temperature vs. Time

In Figures 15 and 16 it can again be seen that the changing temperature does effects the measured data by each module. They also show the magnitude of hysteresis that occurs as a result of rising and falling temperatures. Figure 17 also shows the effects of changing temperatures, but because of the noise in the data, it is more difficult to see the hysteresis. Taking a closer look at just one channel and just one test (Test 3 ) we can see the hysteresis, see Figure 18). 


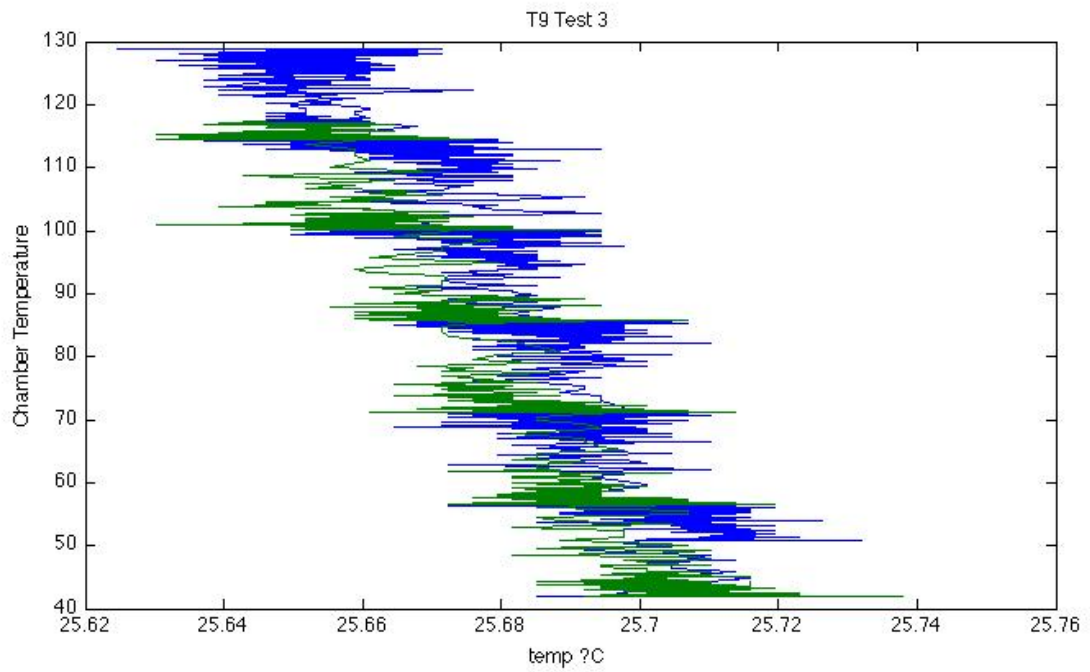

Figure 18 TIM Module 5 Channel 1 (T9) 40 to $130{ }^{\circ} \mathrm{F}$ Blue and 130 to $40^{\circ} \mathrm{F}$ Green

The following plot in Figures 19 to 21 show the data in three dimensions, Time, Chamber Temperature, and Data value.

A1

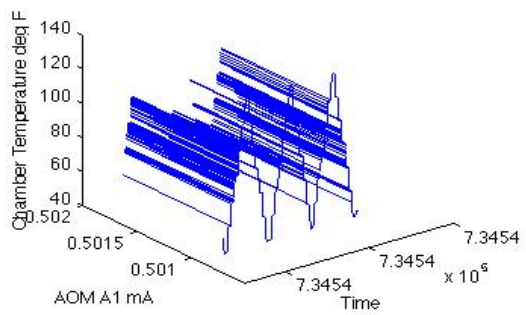

A3

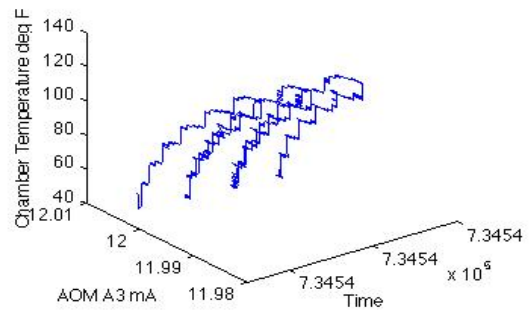

42

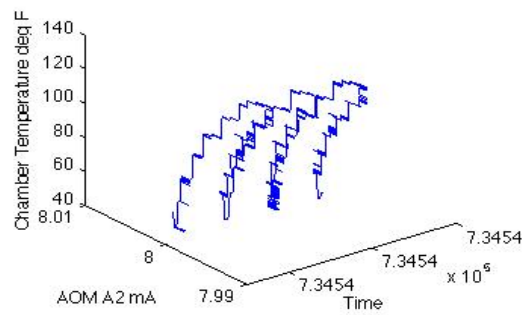

A4

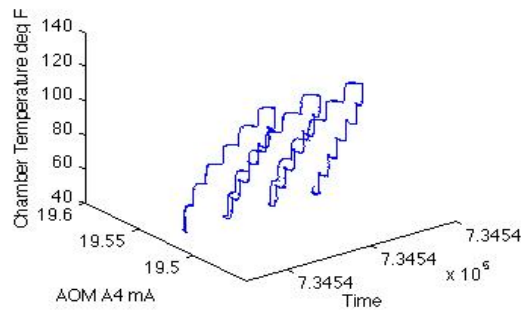

Figure 19 AIM Module 2 Channels DP1 to 4 Time vs. Temp vs. Volts. 
DP1

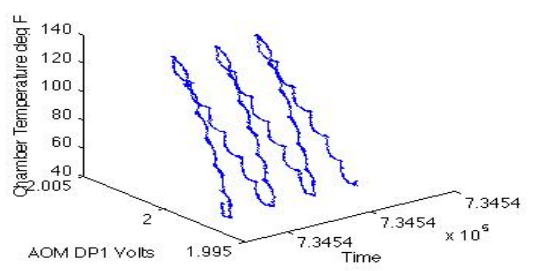

$\mathrm{DP} 3$

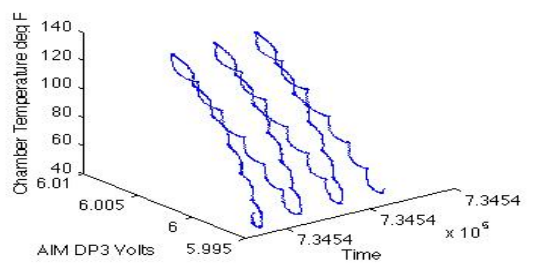

$\mathrm{DP} 2$

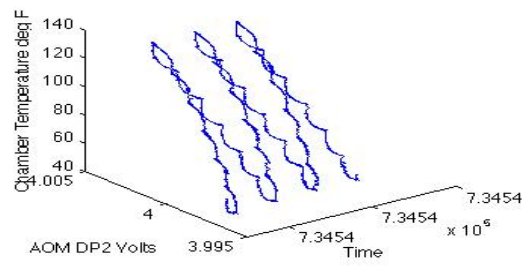

DP4

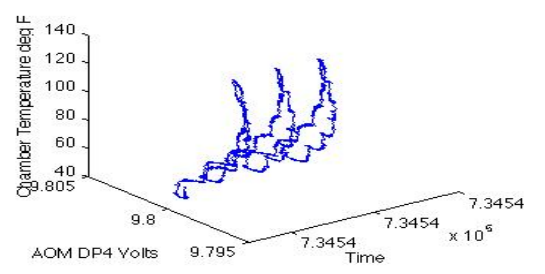

Figure 20 AOM Module 6 Channels A1 to 4 Time vs. Temp vs. mA

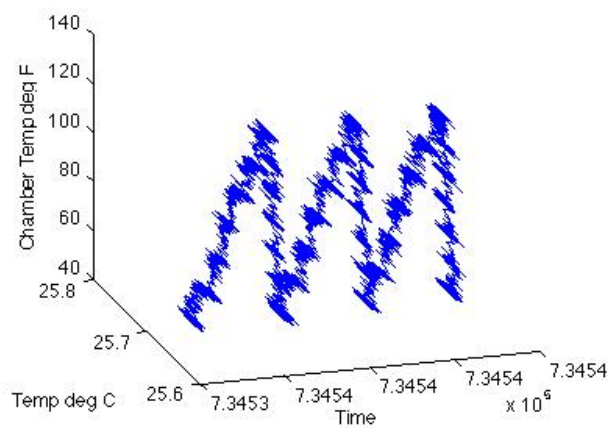

$\mathrm{T} 2, \mathrm{~T} 4, \mathrm{~T} 6, \mathrm{~T} 8, \mathrm{~T} 11$

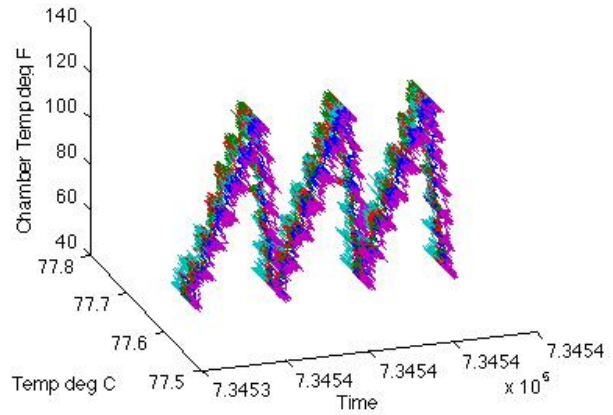

T12

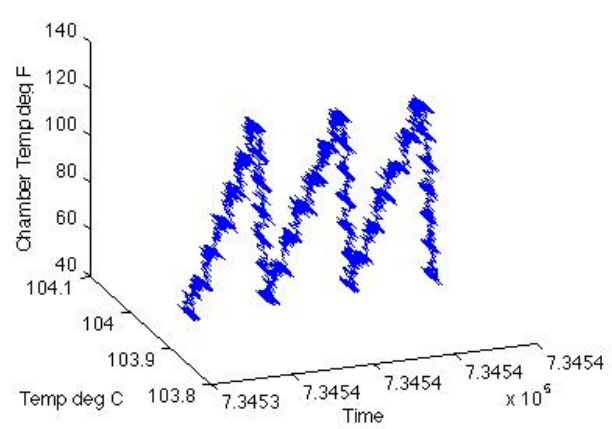

$T 1, T 3, T 5, T 7, T 110$

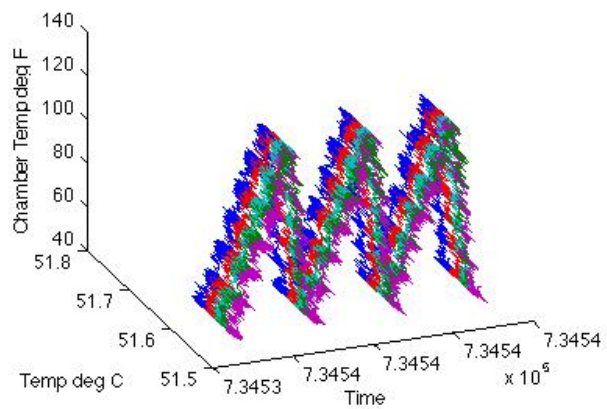

Figure 21 TIM Modules 3,4 and 5 Time vs. Chamber Temp vs. Sensor Temp

The standard deviation for each channel vs. temperature was calculated for the following: 
- Total Standard Deviation for each Channel for all data points including during temperature changes

- Total Standard Deviation for each Channel for each test for just data at steady state temperatures, but including all temperatures

- Standard Deviation for each Channel for each temperature range at steady state, the last hour at each temperature.

Figure 22 illustrates the each of the standard deviations for each channel and each of the three bulleted items above. 


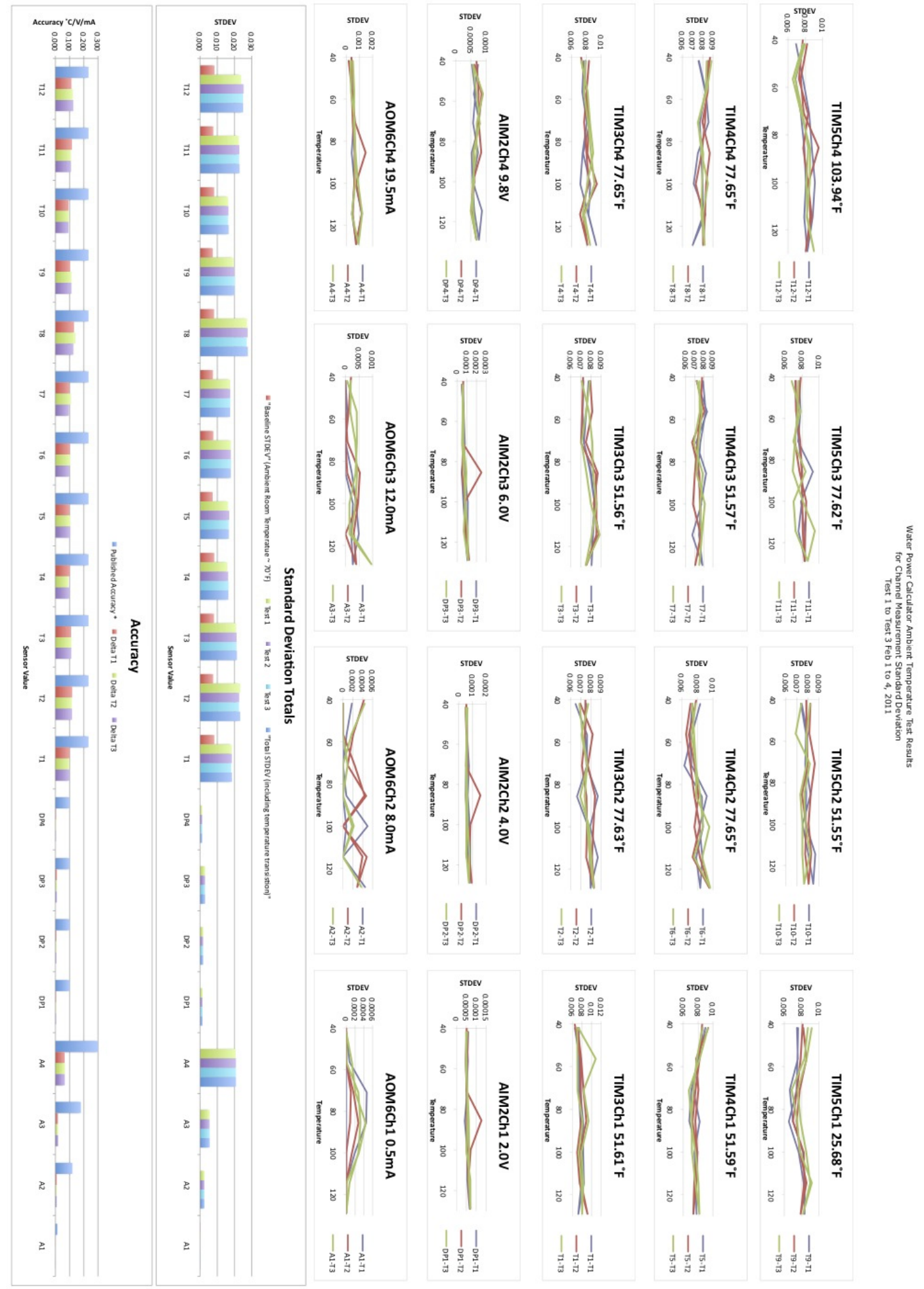

Figure 22 Standard Deviation vs. Temperature *manufactures specifications 
These plots illustrate any hysteresis, which occurs due to the change in temperature and also illustrate the magnitude of deviation that occurs as the temperature changes. The above calculations are done for the range of data over the steady state temperatures only.

The accuracy as published by Moore Industries [ref 7.1] states for each of the modules the ambient operating temperature ranges from $-40^{\circ} \mathrm{C}\left(-40^{\circ} \mathrm{F}\right)$ to $85^{\circ} \mathrm{C}\left(185^{\circ} \mathrm{F}\right)$ for each of the modules. The specific effects of temperature of each module are listed below:

- TIM: Ambient Temperature Accuracy $/{ }^{\circ} \mathrm{C}$ Change $=0.005^{\circ} \mathrm{C}$

- AOM: $+/-0.015 \%$ of full scale, $0-23 \mathrm{~mA}$ (or $0-11 \mathrm{~V}$ ).

- AIM: $+/-0.01 \%$ of full scale, $0-25 \mathrm{~mA}$ (or $-10 \mathrm{~V}$ to $10 \mathrm{~V}$ )

The accuracy "of a measurement system is the degree of closeness of measurements of a quantity to its actual (true) value"[ref 7.2]. For this test, the "true" value is defined as the baseline data collected prior to the start of the chamber testing. In this case, the sensor terminal block and the TIM, AIM, and AOM modules are all at the same ambient temperature, approximately $21^{\circ} \mathrm{C}$. This "baseline" data then becomes our reference point for determining accuracy of the data collected during the tests.

The precision of the data is the degree to which repeated measurements under unchanged conditions show the same results [ref 7.2]. Collecting data over an extended period of time and then plotting the frequency of distribution yields a representation of the reproducibility or repeatability of the data. Figure 23 illustrates this and shows the frequency distribution for the test data for each channel tested grouped according to channel output value. Figure 24 shows the frequency of distribution for each individual channel versus the baseline data for each channel. A frequency of distribution plot is a plot of the number of data points (observations) for a given range of data. For example, we are interested in knowing how many data points fall in the range of 103.86 and 104.02 for the channel of T12. The curve shows the number of observations at each of the temperatures recorded in that range. 


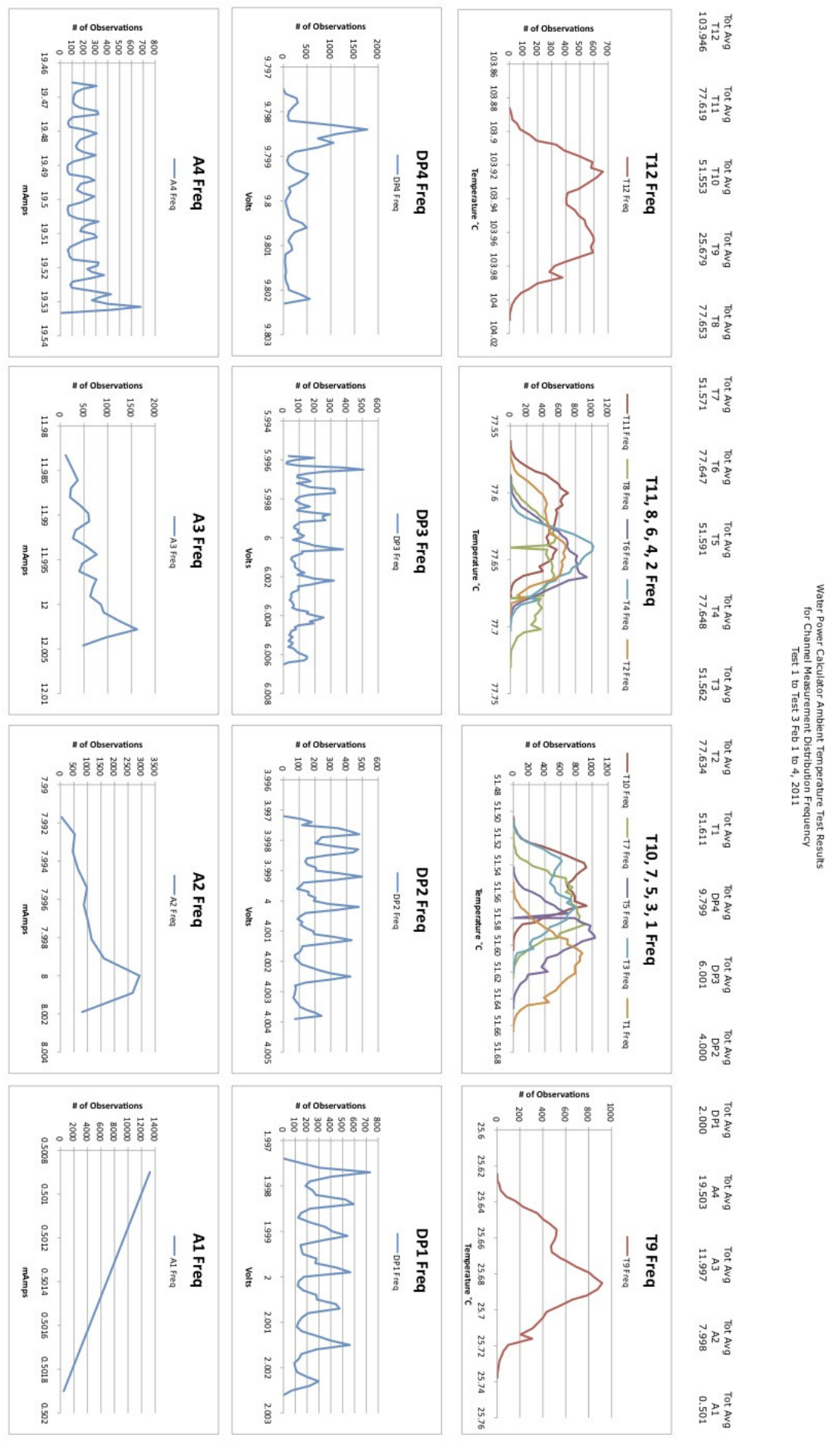

Figure 23 Frequency Distribution of all test results according to Channel output range 


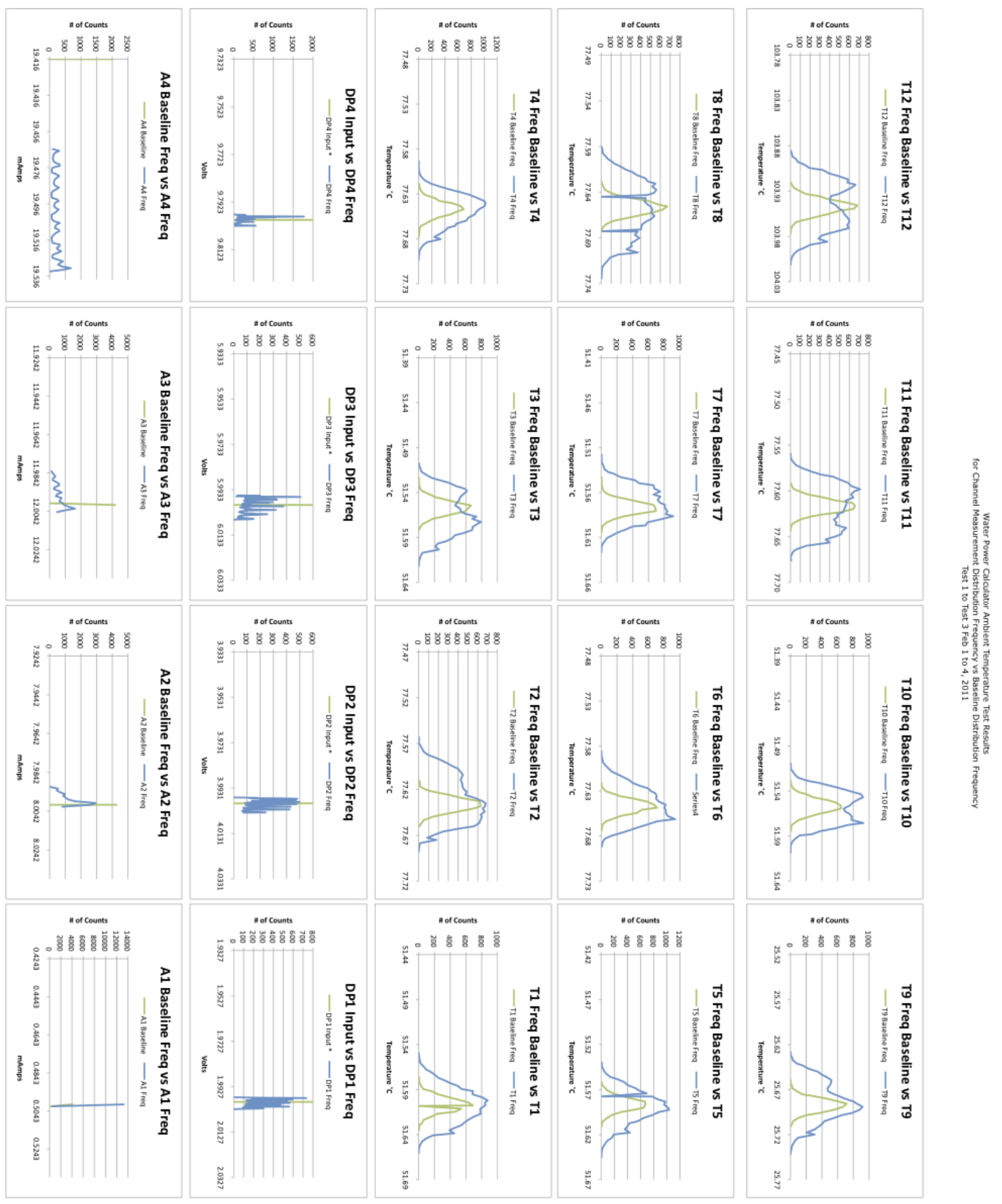

Figure 24 Frequency Distribution of all test results versus baseline data according to channel. 


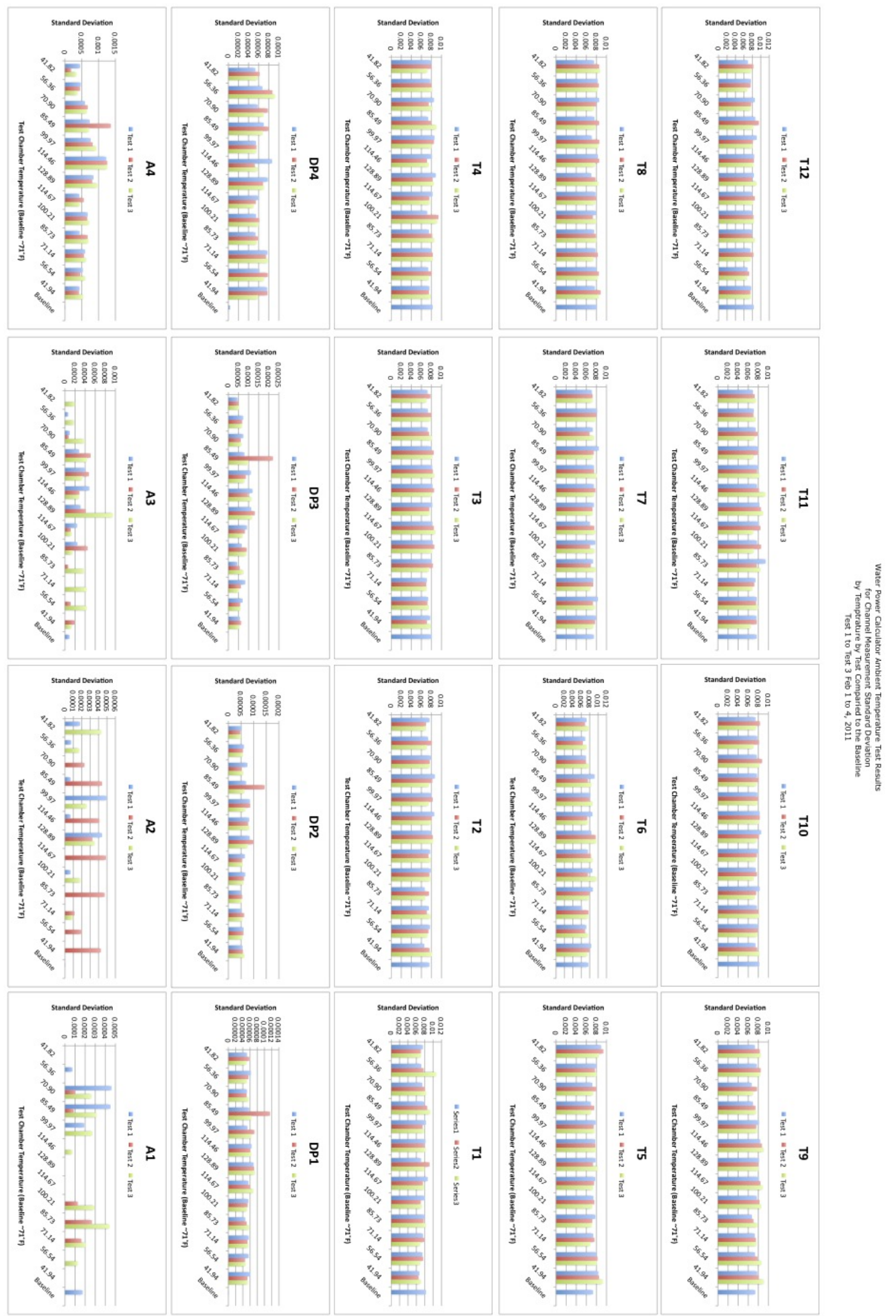

Figure 25 Standard Deviation by Channel by Chamber Temperature by Test 


\subsection{Evaluation}

\subsubsection{Variability in the data for each of the channels is shown in the following tables. The units for each channel are as follows:}

- $\quad \mathrm{T} 1$ to $\mathrm{T} 12{ }^{\circ} \mathrm{C}$

- DP1 to DP4 Volts

- A1 to A4 Milliamps

Table 4 Test Results Summary

\begin{tabular}{|c|c|c|c|c|c|c|c|c|c|c|c|c|}
\hline Channel & DP4 & DP3 & DP2 & DP1 & A4 & $\mathrm{A} 3$ & $A 2$ & $\mathrm{~A} 1$ & & & & \\
\hline STDEV Test 1 & 0.001 & 0.003 & 0.002 & 0.001 & 0.021 & 0.006 & 0.003 & 0.000 & & & & \\
\hline STDEV Test 2 & 0.001 & 0.003 & 0.002 & 0.001 & 0.021 & 0.006 & 0.002 & 0.000 & & & & \\
\hline STDEV Test 3 & 0.001 & 0.003 & 0.002 & 0.001 & 0.021 & 0.006 & 0.003 & 0.000 & & & & \\
\hline Max Test 1 & 9.802 & 6.006 & 4.004 & 2.002 & 19.532 & 12.005 & 8.002 & 0.502 & & & & \\
\hline Max Test 2 & 9.802 & 6.006 & 4.004 & 2.003 & 19.533 & 12.004 & 8.001 & 0.502 & & & & \\
\hline Max Test 3 & 9.802 & 6.007 & 4.004 & 2.003 & 19.532 & 12.004 & 8.001 & 0.502 & & & & \\
\hline Min Test 1 & 9.798 & 5.996 & 3.997 & 1.997 & 19.467 & 11.986 & 7.993 & 0.501 & & & & \\
\hline Min Test 2 & 9.798 & 5.996 & 3.998 & 1.998 & 19.466 & 11.985 & 7.993 & 0.501 & & & & \\
\hline Min Test 3 & 9.798 & 5.996 & 3.998 & 1.998 & 19.466 & 11.983 & 7.992 & 0.501 & & & & \\
\hline Avg Test 1 & 9.795 & 6.000 & 4.000 & 2.000 & 19.503 & 11.998 & 7.999 & 0.501 & & & & \\
\hline Avg Test 2 & 9.795 & 6.001 & 4.000 & 2.000 & 19.503 & 11.997 & 7.998 & 0.501 & & & & \\
\hline Avg Test 3 & 9.795 & 6.001 & 4.000 & 2.000 & 19.503 & 11.996 & 7.998 & 0.501 & & & & \\
\hline Delta Max Test 1 & 0.005 & 0.011 & 0.007 & 0.005 & 0.066 & 0.018 & 0.009 & 0.001 & & & & \\
\hline Delta Max Test 2 & 0.00 & 0.010 & 0.006 & 0.005 & 0.068 & 0.018 & 0.008 & 0.001 & & & & \\
\hline \multicolumn{2}{|c|}{ Delta Max Test 3} & 0.010 & 0.006 & 0.005 & 0.067 & 0.020 & 0.009 & 0.001 & & & & \\
\hline Channel & $\mathrm{T} 12$ & $\mathrm{~T} 11$ & T10 & T9 & $\mathrm{T} 8$ & T7 & T6 & T5 & T4 & T3 & $\mathrm{T} 2$ & $\mathrm{~T} 1$ \\
\hline STDEV Test 1 & 0.024 & 0.023 & 0.016 & 0.019 & 0.027 & 0.017 & 0.018 & 0.016 & 0.016 & 0.021 & 0.023 & 0.018 \\
\hline STDEV Test 2 & 0.025 & 0.023 & 0.017 & 0.020 & 0.028 & 0.018 & 0.018 & 0.017 & 0.016 & 0.021 & 0.023 & 0.018 \\
\hline STDEV Test 3 & 0.025 & 0.023 & 0.016 & 0.020 & 0.027 & 0.018 & 0.018 & 0.017 & 0.017 & 0.021 & 0.023 & 0.018 \\
\hline Max Test 1 & 104.003 & 77.678 & 51.597 & 25.732 & 77.718 & 51.615 & 77.694 & 51.642 & 77.696 & 51.621 & 77.686 & 51.655 \\
\hline Max Test 2 & 104.012 & 77.678 & 51.600 & 25.738 & 77.731 & 51.624 & 77.692 & 51.647 & 77.696 & 51.619 & 77.686 & 51.658 \\
\hline Max Test 3 & 104.012 & 77.675 & 51.604 & 25.738 & 77.720 & 51.619 & 77.694 & 51.647 & 77.703 & 51.619 & 77.692 & 51.664 \\
\hline Min Test 1 & 103.890 & 77.561 & 51.504 & 25.628 & 77.586 & 51.516 & 77.591 & 51.542 & 77.593 & 51.510 & 77.567 & 51.553 \\
\hline Min Test 2 & 103.890 & 77.568 & 51.504 & 25.625 & 77.590 & 51.516 & 77.588 & 51.542 & 77.606 & 51.506 & 77.570 & 51.559 \\
\hline Min Test 3 & 103.886 & 77.565 & 51.511 & 25.625 & 77.593 & 51.523 & 77.594 & 51.542 & 77.602 & 51.506 & 77.574 & 51.565 \\
\hline Avg Test 1 & 103.941 & 77.617 & 51.548 & 25.677 & 77.649 & 51.570 & 77.646 & 51.589 & 77.647 & 51.560 & 77.632 & 51.610 \\
\hline Avg Test 2 & 103.948 & 77.619 & 51.554 & 25.678 & 77.654 & 51.572 & 77.647 & 51.591 & 77.647 & 51.562 & 77.634 & 51.612 \\
\hline Avg Test 3 & 103.950 & 77.621 & 51.557 & 25.681 & 77.657 & 51.573 & 77.649 & 51.592 & 77.649 & 51.563 & 77.636 & 51.613 \\
\hline Delta Max Test 1 & 0.113 & 0.117 & 0.093 & 0.104 & 0.132 & 0.100 & 0.103 & 0.100 & 0.103 & 0.111 & 0.119 & 0.102 \\
\hline Delta Max Test 2 & 0.123 & 0.110 & 0.096 & 0.113 & 0.141 & 0.109 & 0.104 & 0.105 & 0.090 & 0.112 & 0.116 & 0.098 \\
\hline Delta Max Test 3 & 0.126 & 0.110 & 0.093 & 0.113 & 0.127 & 0.096 & 0.100 & 0.105 & 0.101 & 0.112 & 0.118 & 0.100 \\
\hline
\end{tabular}

The maximums and minimums along with the averages for each test are calculated for each of the steady state temperatures ranges. Also the Delta Max or the minimum value subtracted from the maximum value producing the 
maximum measured variability for each of the given channels for each of the given tests.

Table 5 Test Data Overall Totals

\begin{tabular}{|c|c|c|c|c|c|c|c|c|c|c|c|c|c|}
\hline \multirow{2}{*}{$\begin{array}{l}\text { Pen Name } \\
\text { Baseline }\end{array}$} & \multicolumn{2}{|c|}{$\mathrm{T} 12$} & T11 & T10 & T9 & T8 & T7 & T6 & T5 & T4 & T3 & $\mathrm{T} 2$ & T1 \\
\hline & \multicolumn{2}{|c|}{0.008} & 0.008 & 0.008 & 0.007 & 0.008 & 0.008 & 0.008 & 0.007 & 0.008 & 0.008 & 0.008 & 0.008 \\
\hline STDEV Total & \multicolumn{2}{|c|}{0.025} & 0.023 & 0.017 & 0.020 & 0.028 & 0.017 & 0.018 & 0.017 & 0.016 & 0.021 & 0.023 & 0.018 \\
\hline Avg All & \multicolumn{2}{|c|}{103.946} & 77.619 & 51.553 & 25.679 & 77.653 & 51.571 & 77.647 & 51.591 & \multirow[t]{5}{*}{77.648} & \multirow[t]{5}{*}{51.562} & \multirow[t]{5}{*}{77.634} & \multirow[t]{5}{*}{51.612} \\
\hline Pen $\mathrm{Na}$ & & DP4 & DP3 & DP2 & DP1 & A4 & A3 & A2 & $\mathrm{A} 1$ & & & & \\
\hline Baselin & & 0.000 & 0.000 & 0.000 & 0.000 & 0.000 & 0.000 & 0.000 & 0.000 & & & & \\
\hline STDEV & otal & 0.001 & 0.003 & 0.002 & 0.001 & 0.021 & 0.006 & 0.003 & 0.000 & & & & \\
\hline Avg All & & 9.799 & 6.000 & 4.000 & 2.000 & 19.503 & 11.997 & 7.998 & 0.501 & & & & \\
\hline
\end{tabular}

Table 5 summarizes the Baseline Standard Deviation with the "Overall" or the total standard deviation of all of the data from all three tests, including the temperature transition periods. It also includes the average of all of the data. Looking at each of the temperature plots of standard deviation for each of the temperatures in Figure 22. It can be seen that, on average, there is an increase in the standard deviation with an increase of temperature. Following the plot lines give and indication of the hysteresis of the system with regard to temperature decreases. Reviewing Figures 12, 13, 17 and 18 show that plotting the channel output versus the change in chamber temperature shows a shift in readings from the channel. Figure 18 is a plot of a single channel (T9) for test number 3 only. The data shown in blue was recorded during the temperature increase and data shown in green while the temperature decreased. From this we see that when the temperature of the temperature module increases, the reported "temperature" of channel T9 decreases approximately $0.06^{\circ} \mathrm{C}$. The maximum delta from Test 3 for channel T9 is $0.113^{\circ} \mathrm{C}$ (from Table 4), the largest data separation for that channel for Test 3. Figure 11 is the channel plots versus time for the AIM module (DP14). In this case the channel values for 1, 2 and 3 increase with temperature increase. Channel DP4 shows a "tendency" for a downward direction with an increase in temperature of the AIM module. This can also be seen in Figures 19 through 21. Table 4 shows the standard deviation, averages, maximums, minimums and the maximum delta between the maximum and minimum for each of the channels for each test. The values are the total or averaged values for each of the test. A full spread sheet of standard deviation values can been seen in 
Attachment 1. Figure 25 displays the compares the standard deviation for each channel at each chamber temperature for each test against the baseline standard deviation. This representation provides an indication of the accuracy of the data. Each graph of the figure shows that the data for a give channel varies by less then $+/-0.01{ }^{\circ} \mathrm{C}$ for the TIM and less $+/-0.00025$ Volt for the AOM and less then $0.0015 \mathrm{~mA}$ for the AIM. This chart shows that all of the data collected during the temperature stabilized periods are very tightly grouped. However, we need to examine the precision of each channel for each test. Figure 23 is the frequency distribution, or grouping, of all data collected for each channel, for a region of channel output into counts, or number of data points, for the region of channel output. For example, the total number of data points versus a temperature. Each plot shows the curve for all of the data collected. In other words, all of the readings for a given channel will be contained in the area under the curve. Figure 24 shows the frequency distribution for each channel compared to the measured baseline, with the exception of plots DP1 to DP4 were the input voltage is displayed, because the input voltage varied from setup to setup. The scale of the $\mathrm{x}$-axis is the region of tolerance as published in the manufactures specifications, for the TIMS is listed as $0.005^{\circ} \mathrm{C}$ per ${ }^{\circ} \mathrm{C}$ change and for the $\mathrm{AOM}+/-0.015 \%$ of max span per ${ }^{\circ} \mathrm{C}$ and AIM $+/-0.01 \%$ of $\max$ span per ${ }^{\circ} \mathrm{C}$. The baseline for channel A4 plot falls just outside of the manufactures specified accuracy applied to the median value of the test data. As mentioned the setup for the baseline data and the setup for the tests occurred at different locations, it is possible that the input values were not the same. As mentioned earlier, the output of the TIMs decreases as the chamber temperature increases, so the accuracy given for the higher chamber temperature is given by:

$+/-0.005^{\circ} \mathrm{C} /{ }^{\circ} \mathrm{C}$

$-0.005^{*}(54.44-21.11)=-0.167^{\circ} \mathrm{C}$

The accuracy for the low chamber temperature is given by:

$+0.005^{*}(21.11-4.44)=+0.083^{\circ} \mathrm{C}$

The accuracy for the AIM is give by:

$+/-0.01 \% \max \operatorname{span} /{ }^{\circ} \mathrm{C}$

$-0.01 *(10-(10)) *(54.44-21.11) / 100=+/-0.0667^{\circ} \mathrm{V}$ 
$+0.01 *(10-(-10)) * 21.11-4.44) / 100=+0.0333^{\circ} \mathrm{V}$

The accuracy for the AOM is give by:

$+/-0.01 \%$ of $\max \operatorname{span} /{ }^{\circ} \mathrm{C}$

$-0.01 *(23) *(54.44-21.11) / 100=-0.0767 \mathrm{~mA}$

$+0.01 *(23) *(21.11-4.44) / 100=+0.0383 \mathrm{~mA}$

The accuracy is applied to the mean of the baseline, and from the plots we can see that all of the data recorded for each channel fall within the specified accuracy. The channel accuracy is given in Table 6 .

Table 6 Channel Accuracy

\begin{tabular}{|c|c|c|c|c|c|c|c|c|c|c|c|c|}
\hline Channel & $\mathrm{T} 12$ & T11 & T10 & T9 & T8 & T7 & T6 & T5 & T4 & T3 & $\mathrm{T} 2$ & $\mathrm{~T} 1$ \\
\hline span & $\begin{array}{r}110.00 \\
0\end{array}$ & $\begin{array}{r}100.00 \\
0\end{array}$ & $\begin{array}{r}100.00 \\
0\end{array}$ & $\begin{array}{r}100.00 \\
0\end{array}$ & $\begin{array}{r}100.00 \\
0\end{array}$ & $\begin{array}{r}100.00 \\
0\end{array}$ & $\begin{array}{r}100.00 \\
0\end{array}$ & $\begin{array}{r}100.00 \\
0\end{array}$ & $\begin{array}{r}100.00 \\
0\end{array}$ & $\begin{array}{r}100.00 \\
0\end{array}$ & $\begin{array}{r}100.00 \\
0\end{array}$ & $\begin{array}{r}100.00 \\
0\end{array}$ \\
\hline tol span & 0.250 & 0.250 & 0.250 & 0.250 & 0.250 & 0.250 & 0.250 & 0.250 & 0.250 & 0.250 & 0.250 & 0.250 \\
\hline $\begin{array}{l}130^{\circ} \mathrm{C}->.005 /{ }^{\circ} \mathrm{C} \\
4.4->21{ }^{\circ} \mathrm{C}\end{array}$ & 0.167 & 0.167 & 0.167 & 0.167 & 0.167 & 0.167 & 0.167 & 0.167 & 0.167 & 0.167 & 0.167 & 0.167 \\
\hline $.005 /{ }^{\circ} \mathrm{C}$ & $\begin{array}{r}0.083 \\
103.94\end{array}$ & 0.083 & 0.083 & 0.083 & 0.083 & 0.083 & 0.083 & 0.083 & 0.083 & 0.083 & 0.083 & 0.083 \\
\hline Tot Avg & $\begin{array}{r}8 \\
103.78\end{array}$ & 77.619 & 51.552 & 25.683 & 77.653 & 51.575 & 77.649 & 51.588 & 77.647 & 51.556 & 77.640 & 51.611 \\
\hline -tol & $\begin{array}{r}1 \\
104.03\end{array}$ & 77.452 & 51.385 & 25.516 & 77.486 & 51.408 & 77.482 & 51.422 & 77.480 & 51.389 & 77.474 & 51.444 \\
\hline+ tol & 1 & 77.702 & 51.635 & 25.766 & 77.736 & 51.658 & 77.732 & 51.672 & 77.730 & 51.639 & 77.724 & 51.694 \\
\hline Channel & $\begin{array}{l}\text { DP4 } \\
20.000\end{array}$ & $\begin{array}{l}\text { DP3 } \\
20.000\end{array}$ & $\begin{array}{l}\text { DP2 } \\
20.000\end{array}$ & $\begin{array}{l}\text { DP1 } \\
20.000\end{array}$ & $\begin{array}{l}\text { A4 } \\
23.000\end{array}$ & $\begin{array}{l}\mathrm{A} 3 \\
23.000\end{array}$ & $\begin{array}{l}\mathrm{A} 2 \\
23.000\end{array}$ & $\begin{array}{l}\mathrm{A} 1 \\
23.000\end{array}$ & & & & \\
\hline span & 0 & 0 & 0 & 0 & 0 & 0 & 0 & 0 & & & & \\
\hline -tol & 0.0667 & 0.0667 & 0.0667 & 0.0667 & 0.0767 & 0.0767 & 0.0767 & 0.0767 & & & & \\
\hline+ tol & 0.0267 & 0.0333 & 0.0333 & 0.0333 & $\begin{array}{l}0.0383 \\
19.499\end{array}$ & $\begin{array}{l}0.0383 \\
12.000\end{array}$ & 0.0383 & 0.0383 & & & & \\
\hline Tot Avg & 9.7990 & 6.0000 & 3.9998 & 1.9994 & $\begin{array}{r}6 \\
19.422\end{array}$ & $\begin{array}{r}9 \\
11.924\end{array}$ & 8.0009 & 0.5009 & & & & \\
\hline -tol & 9.7323 & 5.9333 & 3.9331 & 1.9327 & $\begin{array}{r}9 \\
19.537\end{array}$ & $\begin{array}{r}2 \\
12.039\end{array}$ & 7.9242 & 0.4243 & & & & \\
\hline+ tol & 9.8257 & 6.0333 & 4.0331 & 2.0327 & 9 & 2 & 8.0392 & 0.5393 & & & & \\
\hline
\end{tabular}

\subsection{Conclusions}

6.3.1 The ambient temperature test results demonstrate that the Moore Industries TIMs, AIM and AOM ambient temperature response meet or exceed the manufactures specifications.

7. References

7.1 Moore Industries-International, Inc, NCS specifications.

7.2 JCGM 200:2008 International vocabulary of metrology Basic and general concepts and associated terms (VIM) 